\title{
Accurate Estimation of In Vivo Inhibition Constants of Inhibitors and Fraction Metabolized of Substrates with Physiologically Based Pharmacokinetic Drug-Drug Interaction Models Incorporating Parent Drugs and Metabolites of Substrates with Cluster Newton Method ${ }^{\mathrm{S}}$
}

\author{
Kenta Yoshida, Kazuya Maeda, Akihiko Konagaya, and Hiroyuki Kusuhara \\ Laboratory of Molecular Pharmacokinetics, Graduate School of Pharmaceutical Sciences, University of Tokyo, Tokyo (K.Y., K.M., \\ H.K.), and Interdisciplinary Graduate School of Science and Engineering, Tokyo Institute of Technology, Yokohama (K.Y., A.K.), \\ Japan
}

Received April 3, 2018; accepted August 16, 2018

\section{ABSTRACT}

The accurate estimation of "in vivo" inhibition constants $\left(K_{i}\right)$ of inhibitors and fraction metabolized $\left(f_{m}\right)$ of substrates is highly important for drug-drug interaction (DDI) prediction based on physiologically based pharmacokinetic (PBPK) models. We hypothesized that analysis of the pharmacokinetic alterations of substrate metabolites in addition to the parent drug would enable accurate estimation of in vivo $K_{\mathrm{i}}$ and $\boldsymbol{f}_{\mathrm{m}}$. Twenty-four pharmacokinetic DDls caused by $\mathrm{P} 450$ inhibition were analyzed with PBPK models using an emerging parameter estimation method, the cluster Newton method, which enables efficient estimation of a large number of parameters to describe the pharmacokinetics of parent and metabolized drugs. For each DDI, two analyses were conducted (with or without substrate metabolite data), and the parameter estimates were compared with each other. In 17 out of 24 cases, inclusion of substrate metabolite information in PBPK analysis improved the reliability of both $K_{\mathrm{i}}$ and $f_{\mathrm{m}}$. Importantly, the estimated $K_{\mathrm{i}}$ for the same inhibitor from different DDI studies was generally consistent, suggesting that the estimated $K_{\mathrm{i}}$ from one study can be reliably used for the prediction of untested DDI cases with different victim drugs. Furthermore, a large discrepancy was observed between the reported in vitro $K_{\mathrm{i}}$ and the in vitro estimates for some inhibitors, and the current in vivo $K_{\mathrm{i}}$ estimates might be used as reference values when optimizing in vitro-in vivo extrapolation strategies. These results demonstrated that better use of substrate metabolite information in PBPK analysis of clinical DDI data can improve reliability of top-down parameter estimation and prediction of untested DDIs.

\section{Introduction}

Pharmacokinetic drug-drug interactions (DDIs) alter the pharmacokinetics of substrate (victim) drugs, consequently leading to adverse reactions that may include lethal events (Huang et al., 2008). For DDIs caused by the inhibition of drug-metabolizing enzymes, the magnitude of the DDI depends on the inhibition constants $\left(K_{\mathrm{i}}\right)$ of the inhibitors against the enzymes and the contribution of the inhibited enzyme to the overall elimination of the substrate drugs $\left(f_{\mathrm{m}}\right)$ as well as the exposure of the inhibitors at the enzyme active site (Ito et al., 1998; Brown et al.,

This work was supported by the Japan Society for the Promotion of Science (JSPS), Japan [a Grant-in-Aid for Scientific Research on Innovative Areas 22136001 and a Grant-in-Aid for Scientific Research (S) 24229002].

https://doi.org/10.1124/dmd.118.081828.

S This article has supplemental material available at dmd.aspetjournals.org.
2005; Obach et al., 2006; Houston and Galetin, 2008; Hisaka et al., 2010). Therefore, the reliability of these two parameters affects the accuracy of the simulated results of the DDI cases.

The physiologically based pharmacokinetic (PBPK) model has been employed for quantitative analysis of clinically reported DDIs (Rowland et al., 2011; Jones et al., 2015; Wagner et al., 2015; Luzon et al., 2017). With the aim of improving the accuracy of PBPK model-based prediction of DDIs, Kato et al. (2008) determined the in vivo $K_{\mathrm{i}}$ values of multiple inhibitor drugs for cytochrome P450 enzymes (P450) by comprehensive analysis of DDI data. They found that the in vivo $K_{\mathrm{i}}$ estimates were smaller than the in vitro $K_{\mathrm{i}}$ values for many inhibitors. They also found that in vivo $K_{\mathrm{i}}$ values showed an up to 100-fold difference, depending on the clinical data. They suggested that the reproducibility of the clinical data from different study groups and the reliability of the fixed $f_{\mathrm{m}}$ values employed in PBPK analysis based on in vitro data are potential causes of such inconsistencies. In fact, a small

ABBREVIATIONS: $\mathrm{A}_{\mathrm{e}}$, amount excreted into urine; $\mathrm{AUCR}$, plasma concentration-time curve ratio; $\mathrm{C}$, concentration of drugs; $\mathrm{CL}_{\text {int }}$, hepatic intrinsic clearance with regard to unbound concentration; CNM, cluster Newton method; DDI, drug-drug interaction; DIDB, University of Washington Metabolism and Transport Drug Interaction Database; $F_{a} F_{g}$, intestinal availability; $f_{\mathrm{B}}$, protein unbound fraction in blood; $f_{\mathrm{m}}$, fraction metabolized; $I$, concentration of inhibitors; $k_{\mathrm{a}}$, absorption rate constant; $k_{\text {transit, }}$, transit rate constant in intestine; $K_{\mathrm{i}}$, inhibition constant for unbound inhibitor concentrations; $K_{\mathrm{i}, \text { total }}$, inhibition constant for total (bound + unbound) inhibitor concentrations; $k_{\mathrm{L}}$, transit rate constant to the large intestine; $K_{\mathrm{p}, \mathrm{h}}$, liver-to-blood concentration ratio; MBI, mechanism-based inhibition; PBPK, physiologically based pharmacokinetic; P450, cytochrome P450; $Q$, blood flow rate; $R_{\mathrm{MBl}}$, degree of inhibition with mechanism-based inhibitors; $\mathrm{SS}_{\text {log,time, }}$, sum of squares of log residuals; $\mathrm{SS}_{\mathrm{log}, \mathrm{Y}}, \mathrm{sum}_{\mathrm{O}}$ of squares of log residuals for the objective function $\mathrm{Y} ; \mathrm{X}$, amount of drugs. 
variation of $f_{\mathrm{m}}$ in a PBPK analysis can have a large impact on the estimated $K_{\mathrm{i}}$.

The ratio of the area under the plasma concentration-time curve (AUCR) of a substrate drug in the presence of a perpetrator drug to that in its absence can be described as eq. 1 , when a perpetrator drug $\left(I_{\mathrm{u}}\right.$ : its plasma protein unbound concentration) competitively inhibits the specific drug metabolizing enzyme(s) (Khojasteh et al., 2011):

$$
\mathrm{AUCR}=\frac{1}{\frac{f_{\mathrm{m}}}{1+\frac{T_{\mathrm{u}}}{K_{\mathrm{i}}}}+\left(1-f_{\mathrm{m}}\right)}
$$

For instance, a 3.3-fold increase in the AUCR of the substrates can be explained either by an $f_{\mathrm{m}}$ of $70 \%$ with $99.6 \%$ inhibition of the enzyme, or an $f_{\mathrm{m}}$ of $90 \%$ with $77 \%$ inhibition. The $K_{\mathrm{i}}$ values varied 70 -fold in these two cases. In other words, $K_{\mathrm{i}}$ and $f_{\mathrm{m}}$ are susceptible to an identifiability problem.

To overcome these difficulties, we need to include additional information related to in vivo $f_{\mathrm{m}}$ or $K_{\mathrm{i}}$. In this study, we focused on the concentration-time profiles of substrate drug metabolites. One can expect that less variety in metabolic enzymes is involved in the formation of metabolites compared with the overall elimination of parent drugs because the elimination of parent drugs is often composed of the formation of multiple metabolites. This specificity can be helpful in accurately determining the alteration in metabolic activity by each enzyme.

Our hypothesis was that an analysis of the pharmacokinetic alterations of the specific substrate metabolites in addition to the substrate parent drug would enable accurate estimation of in vivo $K_{\mathrm{i}}$ and $f_{\mathrm{m}}$. One technical difficulty of this approach is that conventional parameter estimation methods (e.g., Gauss-Newton algorithm) require an estimation of multiple sets of feasible initial parameters to obtain reliable fitted parameters; however, their preparation is laborious and requires a deep understanding of the pharmacokinetics not only for a substrate parent drug but also for the substrate metabolites.

It is challenging to estimate the pharmacokinetic parameters of metabolites due to the paucity of clinical pharmacokinetic data in humans. With this situation in mind, we introduced a new parameter estimation method, which we refer to as the cluster Newton method (CNM) (Yoshida et al., 2013; Aoki et al., 2014). CNM automatically prepares multiple initial parameter sets when the researchers set the broad ranges of the initial parameters, and it suggests multiple sets of fitted parameters as likely solutions. In the present study, we performed PBPK analyses of various DDIs involving the inhibition of P450 enzymes to accurately estimate in vivo $K_{\mathrm{i}}$ and $f_{\mathrm{m}}$ by including substrate metabolite pharmacokinetic information.

\section{Materials and Methods}

Definitions of Pharmacokinetic Parameters. The following pharmacokinetic parameters were used throughout this article: $C$, concentration of drugs; $\mathrm{CL}_{\text {int }}$, hepatic intrinsic clearance with regard to unbound concentration; $F_{\mathrm{a}} F_{\mathrm{g}}$, intestinal availability; $f_{\mathrm{B}}$, protein unbound fraction in blood; $I$, concentration of inhibitors; $k_{\mathrm{a}}$, absorption rate constant; $k_{\text {transit }}$, transit rate constant in intestine; $K_{\mathrm{i}}$, inhibition constant for unbound inhibitor concentrations; $K_{\mathrm{i}, \text { total }}$, inhibition constant for total (bound + unbound) inhibitor concentrations; $k_{\mathrm{LI}}$, transit rate constant to the large intestine; $K_{\mathrm{p}, \mathrm{h}}$, liver-to-blood concentration ratio; $R_{\mathrm{MBI}}$, degree of inhibition with mechanism-based inhibitors; $Q$, blood flow rate; and $X$, amount of drugs.

The following subscripts were used throughout the article: $\mathrm{C}$, central compartment; H, liver compartment; LI, large intestine; Met, metabolite; Peri, peripheral compartment; and Transit_intes, intestinal transit compartment.

Data Source. University of Washington Metabolism and Transport Drug Interaction Database (DIDB: http://www.druginteractioninfo.org) was queried to retrieve in vivo pharmacokinetic interactions involving substrates of
CYP1A2, CYP2C8, CYP2C9, CYP2C19, CYP2D6, and CYP3A until March 2015. Twenty-four DDI cases that met the following criteria were collected (Tables 1 and 2): (1) concentration-time profiles of parent substrates were available, (2) at least the AUC and/or amount excreted into urine $\left(A_{e}\right)$ of the substrate metabolite were available, and (3) information on the isoforms involved in the formation of the metabolites of interest was available in the DIDB. For inhibitors, the following parameters for all metabolic enzymes were collected via the DIDB: inhibition constant $\left(K_{\mathrm{i}}\right)$, inhibitor concentration at half the maximal inhibition potency $\left(\mathrm{IC}_{50}\right)$, maximal inactivation rate constant $\left(k_{\text {inact }}\right)$, and apparent inactivation constant $\left(K_{\mathrm{I}, \mathrm{app}}\right)$.

PBPK Model Development. PBPK models were constructed to describe the pharmacokinetics of substrates (Fig. 1B) and inhibitors (Fig. 1A). The models incorporated central, peripheral, liver, intestinal, and intestinal transit compartments. Formation of substrate metabolites occurs at a liver compartment and at an intestinal compartment. For the hepatic elimination of substrates, P450 enzyme-specific pathways and inhibition by coadministered drugs were included in the model of a DDI case when the following criteria were met:

1. The enzyme was involved in the metabolism of the substrate, according to the in vitro metabolism data.

2. The inhibitor had predicted an $R_{1}$ (competitive inhibition) or $R_{2}$ (mechanism-based inhibition $[\mathrm{MBI}]$ ) value of more than 2 against the enzyme of interest (http://www.fda.gov/downloads/Drugs/ GuidanceComplianceRegulatoryInformation/Guidances/UCM292362.pdf), using geometric mean of the reported $K_{\mathrm{i}}, \mathrm{IC}_{50}, k_{\text {inact }}$, and $K_{\mathrm{I} \text {, app }}$.

When the $\mathrm{R}_{2}$ criterion was met (clarithromycin on CYP3A, fluoxetine on CYP2C19 and CYP3A, or paroxetine on CYP2D6), the potency of the MBI by inhibitors was described with the $\mathrm{R}_{\mathrm{MBI}}$ parameter in the PBPK model, as described in the next section, under an assumption that the inhibition potency by MBI at the steady-state is constant; otherwise, $K_{\mathrm{i}}$ was used to describe the inhibition potencies of inhibitors on hepatic enzymes.

In addition, the elimination pathways with other P450 enzymes or non-P450 enzymes were included to form "other pathways" in the model. P450 enzymespecific pathways were further divided into the formation of each substrate metabolite, including "other metabolites" that were not quantified in reported DDIs. Similarly, P450 enzyme-specific and other elimination pathways were included in the eliminations of substrate metabolites.

Intestinal metabolism by CYP3A and its inhibition by coadministered drugs were considered when the following criteria were met:

1. CYP3A was involved in the metabolism of the substrate, according to the in vitro metabolism data.

2. The estimated $F_{\mathrm{a}} F_{\mathrm{g}}$ of the substrate was less than 0.95 (Table 3 ).

3. The inhibitor used in a clinical study has a predicted $\mathrm{R}_{1}$ value (using inhibitor concentration of dose $/ 250 \mathrm{ml}$ ) of more than 11 against CYP3A http://www. fda.gov/downloads/Drugs/GuidanceComplianceRegulatoryInformation/ Guidances/UCM292362.pdf) using the geometric mean of the reported $K_{\mathrm{i}}$ and $\mathrm{IC}_{50}$.

The potency of intestinal enzyme inhibition by inhibitors was described with the $R_{\text {intes }}$ parameter in our PBPK model as a constant value due to the following reasons/assumptions: 1) our PBPK model does not make an inference on effective intestinal inhibitor concentration, which makes estimation of $K_{\mathrm{i}}$ difficult; and 2) the intestinal inhibition matters mainly at the early time points (before intestinal absorption of substrate drugs is finished), and time-dependent change in the magnitude of intestinal inhibition has less influence on substrate kinetics compared with the inhibition of hepatic enzymes. This assumption is supported by the fact that estimated $k_{\mathrm{a}}$ of all of the substrates has geometric mean of $\geq 0.6$ hour $^{-1}$ (a halflife of approximately 1 hour or less).

Elimination pathways with other P450 enzymes or non-P450 enzymes were included to form "other pathways" in the model.

Simulations with PBPK Models. All the simulations were performed with the PBPK models described in Fig. 1 and in the following equations. First, hepatic or renal clearance and intestinal kinetic constants were calculated, where $i, j$, or $k$ represent $\mathrm{P} 450$ enzymes, metabolites, or inhibitors, and a single prime (') denotes the parameter values when inhibitor(s) were coadministered: 
TABLE 1

List of inhibitors analyzed in this study

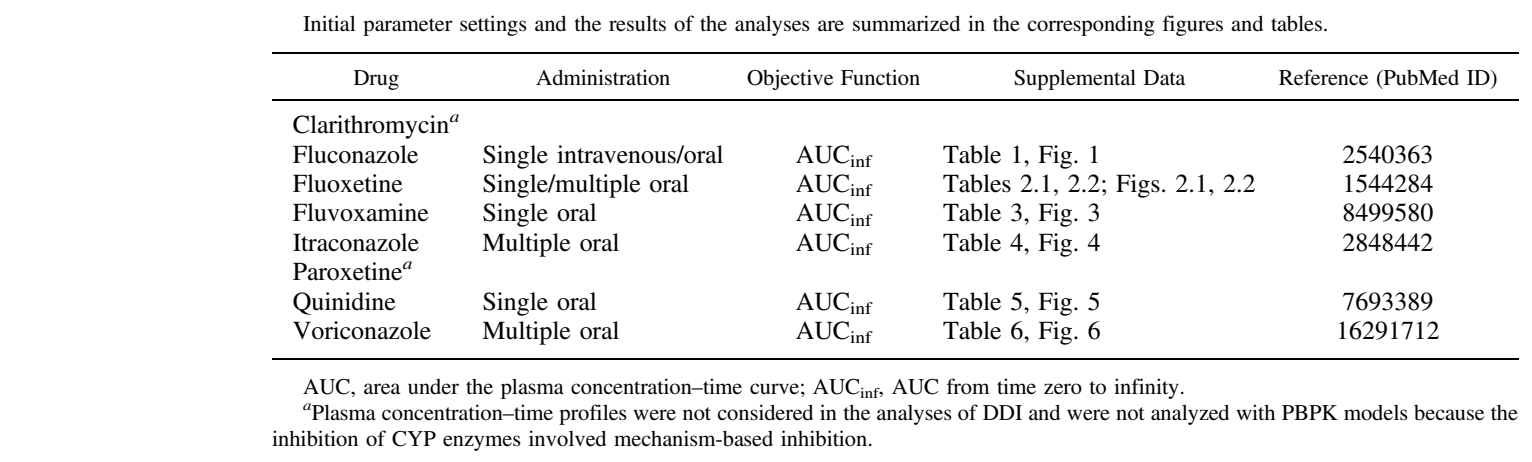

$$
\begin{aligned}
& f_{\mathrm{B}} \mathrm{CL}_{\mathrm{CYP}_{\mathrm{A}}}=f_{\mathrm{B}} \mathrm{CL}_{\text {int }} \cdot \frac{\mathrm{CL}_{\mathrm{CYP}_{\mathrm{A}}} / \mathrm{CL}_{\text {other }}}{\sum_{i}\left(\mathrm{CL}_{\mathrm{CYP}_{\mathrm{i}}} / \mathrm{CL}_{\text {other }}\right)+1} \\
& f_{\mathrm{B}} \mathrm{CL}_{\text {other }}=f_{\mathrm{B}} \mathrm{CL}_{\text {int }} \cdot \frac{1}{\sum_{i}\left(\mathrm{CL}_{\mathrm{CYP}_{\mathrm{i}}} / \mathrm{CL}_{\text {other }}\right)+1} \\
& f_{\mathrm{B}} \mathrm{CL}_{\mathrm{CYP}_{\mathrm{A}}, \mathrm{Met}_{\mathrm{a}}}=f_{\mathrm{B}} \mathrm{CL}_{\mathrm{CYP}_{\mathrm{A}}} \cdot \frac{\mathrm{CL}_{\mathrm{CYP}_{\mathrm{A}}, \mathrm{Met}_{\mathrm{a}}} / \mathrm{CL}_{\mathrm{CYP}_{\mathrm{A}}, \text { other }}}{\sum_{j}\left(\mathrm{CL}_{\mathrm{CYP}_{\mathrm{A}}, \mathrm{Met}_{\mathrm{j}}} / \mathrm{CL}_{\mathrm{CYP}_{\mathrm{A}}, \text { other }}\right)+1} \\
& f_{\mathrm{B}} \mathrm{CL}_{\text {other,Met }}=f_{\mathrm{B}} \mathrm{CL}_{\text {other }} \cdot \frac{\mathrm{CL}_{\text {other,Met }} / \mathrm{CL}_{\text {other,other }}}{\sum_{j}\left(\mathrm{CL}_{\text {other,Met }_{\mathrm{j}}} / \mathrm{CL}_{\text {other,other }}\right)+1} \\
& f_{\mathrm{B}} \mathrm{CL}_{\text {other,other }}=f_{\mathrm{B}} \mathrm{CL}_{\text {other }} \cdot \frac{1}{\sum_{j}\left(\mathrm{CL}_{\text {other,Met }_{\mathrm{j}}} / \mathrm{CL}_{\text {other,other }}\right)+1} \\
& f_{\mathrm{B}} \mathrm{CL}_{\mathrm{CYP}_{\mathrm{A}}, \mathrm{Met}_{\mathrm{a}}}=f_{\mathrm{B}} \mathrm{CL}_{\mathrm{CYP}_{\mathrm{A}}, \mathrm{Met}_{\mathrm{a}}} \cdot \frac{1}{1+\sum_{k}\left(I_{H, k} / K_{i, \text { total }, k, \mathrm{CYP}_{\mathrm{A}}}\right)} \cdot \frac{1}{\Pi_{k} R_{\mathrm{MBI}, k, \mathrm{CYP}_{\mathrm{A}}}} \\
& \mathrm{CL}_{R}=\frac{Q_{R} \mathrm{CL}_{R, \text { int,app }}}{Q_{R}+\mathrm{CL}_{R, \text { int,app }}} \\
& k_{\mathrm{LI}}=k_{a} \cdot \frac{1-F_{a} F_{g}}{F_{a} F_{g}} \cdot \frac{1}{\sum_{i}\left(k_{\mathrm{CYP} 3 \mathrm{~A}, \mathrm{CYP}_{i}} / k_{\mathrm{LI}}\right)+1}
\end{aligned}
$$

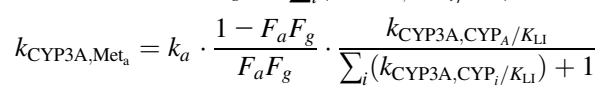

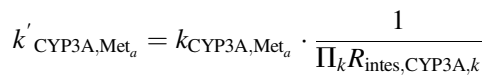

Using these parameters, the following ordinary differential equations were solved numerically:

Equations for Substrates.

Central compartment (C):

$$
V_{C} \frac{d C_{c}}{d t}=Q_{H} \frac{C_{H}}{K_{P, H}}+k_{21} X_{\text {peri }}-\left(Q_{H}+\mathrm{CL}_{12}+\mathrm{CL}_{R}\right) C_{C}
$$

Peripheral compartment (Peri):

$$
\frac{d X_{\text {Peri }}}{d t}=-k_{21} X_{\text {Peri }}+\mathrm{CL}_{12} C_{c}
$$

Intestinal and intestinal transit compartment (Transit_intes):

$$
\begin{aligned}
& \frac{d X_{\text {Transit_intes }}}{d t}=-k_{a, \text { transit }} X_{\text {Transit_intes }} \\
& \frac{d X_{\text {Intestine }}}{d t}=k_{a, \text { transit }} X_{\text {Transit_intes }}-\left(k_{a}+k_{\mathrm{LI}}+\sum_{j} k_{\mathrm{CYP} 3 \mathrm{~A}, \text { Met }_{j}}\right) X_{\text {Intestine }}
\end{aligned}
$$

Liver compartment $(\mathrm{H})$ :

$$
V_{H} \frac{d C_{H}}{d t}=Q_{H} \cdot\left(C_{C}-\frac{C_{H}}{K_{P, H}}\right)-\sum_{i} \sum_{j} f_{B} \mathrm{CL}_{\mathrm{CYP}_{i}, \mathrm{Met}_{j}} \cdot \frac{C_{H}}{K_{P, H}}
$$

Equations for Metabolite (a) of Substrates. Central compartment:

$$
V_{C} \frac{d C_{C}}{d t}=Q_{H} \frac{C_{H}}{K_{P, H}}+k_{21} X_{P e r i}-\left(Q_{H}+\mathrm{CL}_{12}+\mathrm{CL}_{R}\right) C_{C}
$$

Peripheral compartment:

$$
\frac{d X_{\text {Peri }}}{d t}=-k_{21} X_{\text {Peri }}+\mathrm{CL}_{12} C_{C}
$$

Intestinal compartment:

$$
\frac{d X_{\text {Intestine }}}{d t}=k_{\mathrm{CYP} 3 \mathrm{~A}, \text { Met }_{a}, \text { parent }} X_{\text {Transit_intes,parent }}-k_{a} X_{\text {Intestine }}
$$

Liver compartment:

$$
\begin{aligned}
V_{H} \frac{d C_{H}}{d t}= & Q_{H} \cdot\left(C_{C}-\frac{C_{H}}{K_{P, H}}\right)-\sum_{i} f_{B} \mathrm{CL}_{\mathrm{CYP}_{i}} \cdot \frac{C_{H}}{K_{P, H}} \\
& +\sum_{i} f_{B} \mathrm{CL}_{\mathrm{CYP}_{i}, \text { Met }_{a, \text { arent }}} \cdot \frac{C_{H, \text { parent }}}{K_{P, H}}
\end{aligned}
$$

Equations for Inhibitors.

Central compartment:

$$
V_{C} \frac{d C_{C}}{d t}=Q_{H} \frac{C_{H}}{K_{P, H}}+k_{21} X_{\text {Peri }}-\left(Q_{H}+\mathrm{CL}_{12}+\mathrm{CL}_{R}\right) C_{C}
$$

Peripheral compartment:

$$
\frac{d X_{\text {Peri }}}{d t}=-k_{21} X_{\text {Peri }}+\mathrm{CL}_{12} C_{C}
$$

Intestinal and intestinal transit compartment:

$$
\begin{gathered}
\frac{d X_{\text {Transit_intes }}}{d t}=-k_{a, \text { transit }} X_{\text {Transit_intes }} \\
\frac{d X_{\text {Intestine }}}{d t}=k_{a, \text { transit }} X_{\text {Transit_intes }}-\frac{k_{a}}{F_{a} F_{g}} X_{\text {Intestine }}
\end{gathered}
$$

Liver compartment:

$$
V_{H} \frac{d_{C H}}{d t}=Q_{H} \cdot\left(C_{C}-\frac{C_{H}}{K_{P, H}}\right)-f_{B} \mathrm{CL}_{\mathrm{int}} \cdot \frac{C_{H}}{K_{P, H}}
$$

Parameter Settings. The following physiologic and pharmacokinetic parameters were fixed throughout the analyses: $Q_{\mathrm{H}}, V_{\mathrm{H}}$, dose, and $F_{a} F_{g}$. The $F_{a} F_{g}$ was calculated with eq. 26 (Table 3 ):

$$
F_{a} F_{g}=F \cdot \frac{Q_{H}}{Q_{H}-\left(\mathrm{CL}_{\mathrm{tot}}-\mathrm{CL}_{R}\right)}
$$

If the calculated $F_{a} F_{g}$ was larger than 0.95 , we assumed $F_{a} F_{g}$ was equal to 1 . The $K_{\mathrm{p}, \mathrm{h}}$ of the inhibitors was fixed to predicted values by methods reported 
TABLE 2

List of drug-drug interactions analyzed in this study

Initial parameter settings and the results of the analyses are summarized in the corresponding figures and tables.

\begin{tabular}{|c|c|c|c|c|c|c|c|c|c|}
\hline \multirow{2}{*}{ Substrates } & \multirow{2}{*}{ Metabolites } & \multirow{2}{*}{ Inhibitors } & \multirow{2}{*}{$\begin{array}{l}\text { Putative Enzyme(s) } \\
\text { Involved }\end{array}$} & \multirow{2}{*}{ AUCR } & \multirow{2}{*}{$\begin{array}{c}\text { ID } \\
\text { Number }\end{array}$} & \multirow{2}{*}{ Additional Data $^{a}$} & \multicolumn{2}{|c|}{ Objective Function } & \multirow{2}{*}{$\begin{array}{c}\text { Reference } \\
\text { (PubMed ID) }\end{array}$} \\
\hline & & & & & & & Parent & Metabolite & \\
\hline Chlorpromazine & 7-Hydroxy chlorpromazine & $\begin{array}{l}\text { Quinidine } \\
\text { (166 mg) }\end{array}$ & CYP2D6, CYP3A & 1.40 & 1 & Table S7, Fig. S7 & $\mathrm{AUC}_{\text {inf }}$ & $\mathrm{AUC}_{\mathrm{inf}}$ & 8739822 \\
\hline \multirow[t]{2}{*}{ Desipramine } & \multirow[t]{2}{*}{ 2-Hydroxy desipramine } & \multirow[t]{2}{*}{$\begin{array}{l}\text { Fluoxetine } \\
\text { (60 mg) }\end{array}$} & \multirow[t]{2}{*}{ CYP2D6 } & $2.58^{b}$ & 2 & $\begin{array}{l}\text { Table S8.1, Fig. } \\
\quad \text { S8.1 }\end{array}$ & \multirow[t]{2}{*}{$\mathrm{AUC}_{\mathrm{inf}}$} & \multirow[t]{2}{*}{$A_{e}$} & \multirow[t]{2}{*}{1544284} \\
\hline & & & & $10.6^{c}$ & 3 & $\begin{array}{l}\text { Table S8.2, Fig. } \\
\text { S8.2 }\end{array}$ & & & \\
\hline \multirow[t]{2}{*}{ Fentanyl } & \multirow[t]{2}{*}{ Norfentanyl } & $\begin{array}{l}\text { Fluconazole } \\
(200 \mathrm{mg})\end{array}$ & CYP3A & 1.26 & 4 & $\begin{array}{l}\text { Table S9.1, Fig. } \\
\text { S9.1 }\end{array}$ & \multirow[t]{2}{*}{$\mathrm{AUC}_{\mathrm{inf}}$} & \multirow[t]{2}{*}{$\mathrm{AUC}_{\mathrm{inf}}$} & \multirow[t]{2}{*}{17987285} \\
\hline & & $\begin{array}{l}\text { Voriconazole } \\
\text { (200 mg) }\end{array}$ & CYP3A & 1.39 & 5 & $\begin{array}{l}\text { Table S9.2, Fig. } \\
\text { S9.2 }\end{array}$ & & & \\
\hline \multirow[t]{2}{*}{ Flurbiprofen } & \multirow[t]{2}{*}{ 4'-Hydroxy flurbiprofen } & \multirow[t]{2}{*}{$\begin{array}{l}\text { Fluconazole } \\
(200 \mathrm{mg})\end{array}$} & \multirow[t]{2}{*}{ CYP2C9 } & 1.75 & 6 & $\begin{array}{l}\text { Fig. 2/Table S.10.1, } \\
\text { Fig. S10.1 }\end{array}$ & \multirow[t]{2}{*}{ AUC } & \multirow[t]{2}{*}{ AUC } & 22943633 \\
\hline & & & & 2.02 & 7 & $\begin{array}{l}\text { Table S10.2, Fig. } \\
\text { S10.2 }\end{array}$ & & & 23047652 \\
\hline Hydrocodone & Hydromorphone & $\begin{array}{l}\text { Quinidine } \\
\text { (83 mg) }\end{array}$ & CYP2D6 & 1.21 & 8 & Table S11, Fig. S11 & $\mathrm{AUC}_{\text {inf }}$ & $\mathrm{AUC}_{\mathrm{inf}}$ & 7693389 \\
\hline \multirow[t]{2}{*}{ Imipramine } & \multirow[t]{2}{*}{$\begin{array}{l}\text { 2-Hydroxy imipramine, } \\
\text { desipramine }\end{array}$} & \multirow[t]{2}{*}{$\begin{array}{l}\text { Fluoxetine } \\
\text { (60 mg) }\end{array}$} & \multirow{2}{*}{$\begin{array}{l}\text { CYP2D6, } \\
\text { CYP2C19, } \\
\text { CYP3A }\end{array}$} & $2.08^{b}$ & 9 & $\begin{array}{l}\text { Table S12.1, Fig. } \\
\quad \text { S12.1 }\end{array}$ & $\mathrm{AUC}_{\mathrm{inf}}$ & $\mathrm{AUC}_{\mathrm{inf}} / \mathrm{A}_{\mathrm{e}}$ & 1544284 \\
\hline & & & & $3.56^{c}$ & 10 & $\begin{array}{l}\text { Table S12.2, Fig. } \\
\text { S12.2 }\end{array}$ & & & \\
\hline Lansoprazole & $\begin{array}{l}\text { 5-Hydroxy lansoprazole, } \\
\text { lansoprazole sulfone }\end{array}$ & $\begin{array}{l}\text { Fluvoxamine } \\
\quad(25 \mathrm{mg})\end{array}$ & CYP2C19 & $4.00^{d}$ & 11 & $\begin{array}{l}\text { Table S13.1, Fig. } \\
\quad \text { S13.1 }\end{array}$ & $\mathrm{AUC}_{\mathrm{inf}}$ & $\mathrm{AUC}_{\mathrm{inf}}$ & 15496639 \\
\hline & & & & $2.50^{e}$ & 12 & $\begin{array}{l}\text { Table S13.2, Fig } \\
\quad \text { S13.2 }\end{array}$ & & & \\
\hline & & $\begin{array}{l}\text { Clarithromycin } \\
\quad(400 \mathrm{mg})\end{array}$ & CYP3A & $1.38^{d}$ & 13 & $\begin{array}{l}\text { Table S13.3, Fig. } \\
\quad \text { S13.3 }\end{array}$ & & & 15752376 \\
\hline & & & & $1.76^{e}$ & 14 & $\begin{array}{l}\text { Table S13.4, Fig. } \\
\quad \text { S13.4 }\end{array}$ & & & \\
\hline & & & & $1.81^{f}$ & 15 & $\begin{array}{l}\text { Table S13.5, Fig. } \\
\quad \text { S13.5 }\end{array}$ & & & \\
\hline Losartan & EXP-3174 & $\begin{array}{l}\text { Fluconazole } \\
\text { (200 mg) }\end{array}$ & CYP2C9, CYP3A & 1.69 & 16 & $\begin{array}{l}\text { Table S14.1, Fig. } \\
\text { S14.1 }\end{array}$ & $\mathrm{AUC}_{\text {inf }}$ & $\mathrm{AUC}_{\mathrm{inf}}$ & 9357393 \\
\hline & & & & 1.27 & 17 & $\begin{array}{l}\text { Table S14.2, Fig. } \\
\quad \text { S14.2 }\end{array}$ & & & 9551703 \\
\hline Omeprazole & $\begin{array}{l}\text { 5-Hydroxy omeprazole, } \\
\text { omeprazole sulfone }\end{array}$ & $\begin{array}{l}\text { Fluvoxamine } \\
\quad(25 \mathrm{mg})\end{array}$ & CYP2C19 & $5.62^{d}$ & 18 & $\begin{array}{l}\text { Table S15.1, Fig. } \\
\quad \text { S15.1 }\end{array}$ & $\mathrm{AUC}_{\mathrm{inf}}$ & $\mathrm{AUClAUC}_{\mathrm{inf}}$ & 15025747 \\
\hline & & & & $2.38^{e}$ & 19 & $\begin{array}{l}\text { Table S15.2, Fig. } \\
\quad \text { S15.2 }\end{array}$ & & & \\
\hline Oxycodone & Noroxycodone, oxymorphone & $\begin{array}{l}\text { Quinidine } \\
\text { (166 mg) }\end{array}$ & CYP2D6 & 1.13 & 20 & $\begin{array}{l}\text { Table S16.1, Fig. } \\
\quad \text { S16.1 }\end{array}$ & $\mathrm{AUC}_{\mathrm{inf}}$ & AUC/AUC $_{\text {inf }}$ & 9871425 \\
\hline & & $\begin{array}{l}\text { Voriconazole } \\
\text { (200 mg) }\end{array}$ & CYP3A & 3.57 & 21 & $\begin{array}{l}\text { Table S16.2, Fig. } \\
\quad \text { S16.2 }\end{array}$ & & & 18836708 \\
\hline & & $\begin{array}{l}\text { Itraconazole } \\
(200 \mathrm{mg})\end{array}$ & CYP3A & 2.43 & 22 & $\begin{array}{l}\text { Table S16.3, Fig. } \\
\quad \text { S16.3 }\end{array}$ & & & 20076952 \\
\hline & & $\begin{array}{l}\text { Paroxetine } \\
(20 \mathrm{mg})\end{array}$ & CYP2D6 & 1.11 & 23 & $\begin{array}{l}\text { Table S16.4, Fig. } \\
\quad \text { S16.4 }\end{array}$ & & & 20642550 \\
\hline Ropivacaine & $(S)-2^{\prime}, 6^{\prime}$-pipecoloxylidide & $\begin{array}{l}\text { Itraconazole } \\
(200 \mathrm{mg})\end{array}$ & CYP3A & 1.23 & 24 & Table S17, Fig. S17 & $\mathrm{AUC}_{\mathrm{inf}}$ & AUC & 11322176 \\
\hline
\end{tabular}

$\mathrm{AUC}$, area under the plasma concentration-time curve; $\mathrm{AUC}_{\mathrm{inf}}$, $\mathrm{AUC}$ from time 0 to infinity.

${ }^{a}$ Tables and figures indicated with an $\mathrm{S}$ are found in the supplemental data.

${ }^{b}$ Fluoxetine single dose.

${ }^{c}$ Fluoxetine multiple dose.

${ }^{d}$ CYP2C19 extensive metabolizer (EM)

${ }^{e} \mathrm{CYP} 2 \mathrm{C} 19$ intermediate metabolizer (IM).

${ }^{f} \mathrm{CYP} 2 \mathrm{C} 19$ poor metabolizer (PM).

elsewhere (Rodgers et al., 2005; Rodgers and Rowland, 2006) using clogP and pKa obtained with Scifinder Scholar (Chemical Abstracts Service, Columbus, $\mathrm{OH})$. All the other parameters were estimated by CNM.

The initial ranges of $V_{c}$ were set as $0.0817-7.431 / \mathrm{kg}$ because the lower boundary was set to be $10 \%$ higher than the lowest limit of parameter value $($ blood volume $=0.07431 / \mathrm{kg})($ Davies and Morris, 1993) to avoid the infinite transformed initial value (see "Transformations of Parameters") when the initial parameter is equal to its lower limit, except for fluoxetine, desipramine, and imipramine $(0.743-74.3 \mathrm{l} / \mathrm{kg})$ where large elimination half-lives were observed. The initial ranges of $k_{\mathrm{a}}$ were set as $0.2-6.0 \mathrm{hour}^{-1}$, considering a gastric emptying rate of 6 hour $^{-1}$ (Ito et al., 1998). The same ranges were used for $k_{\text {transit. }}$
The initial ranges of $f_{\mathrm{B}} \mathrm{CL}_{\text {int }}$ were set as $1 / 10$-fold to 10 -fold of the total body clearance of substrates (control group) or inhibitors. When the peripheral compartment is needed to reproduce the observed concentration-time profiles, the same ranges were used for $\mathrm{CL}_{12}$ and $k_{21}$ as $f_{\mathrm{B}} \mathrm{CL}_{\text {int }}$. For fluconazole, larger ranges of $\mathrm{CL}_{12}$ and $\mathrm{k}_{21}$ were needed to reproduce clinical observations. These

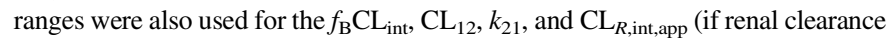
is unknown) of substrate metabolites, except for EXP3194 (a metabolite of losartan) and noroxycodone (a metabolite of oxycodone), where smaller ranges were needed to reproduce clinical observations. We used $0.03-30$ as the initial range for the ratios of CYP enzyme-selective pathways to the other pathway in the overall elimination of substrates, or the ratios of the substrate metabolites' formations to the other pathway in the CYP enzyme-selective pathways; the 
A

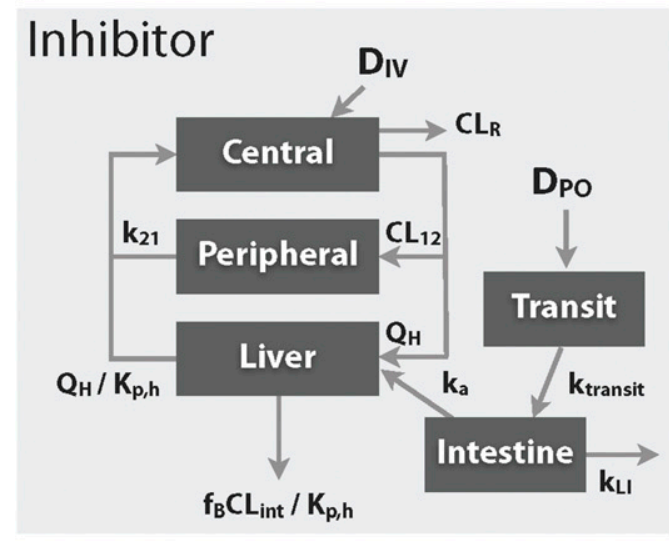

B

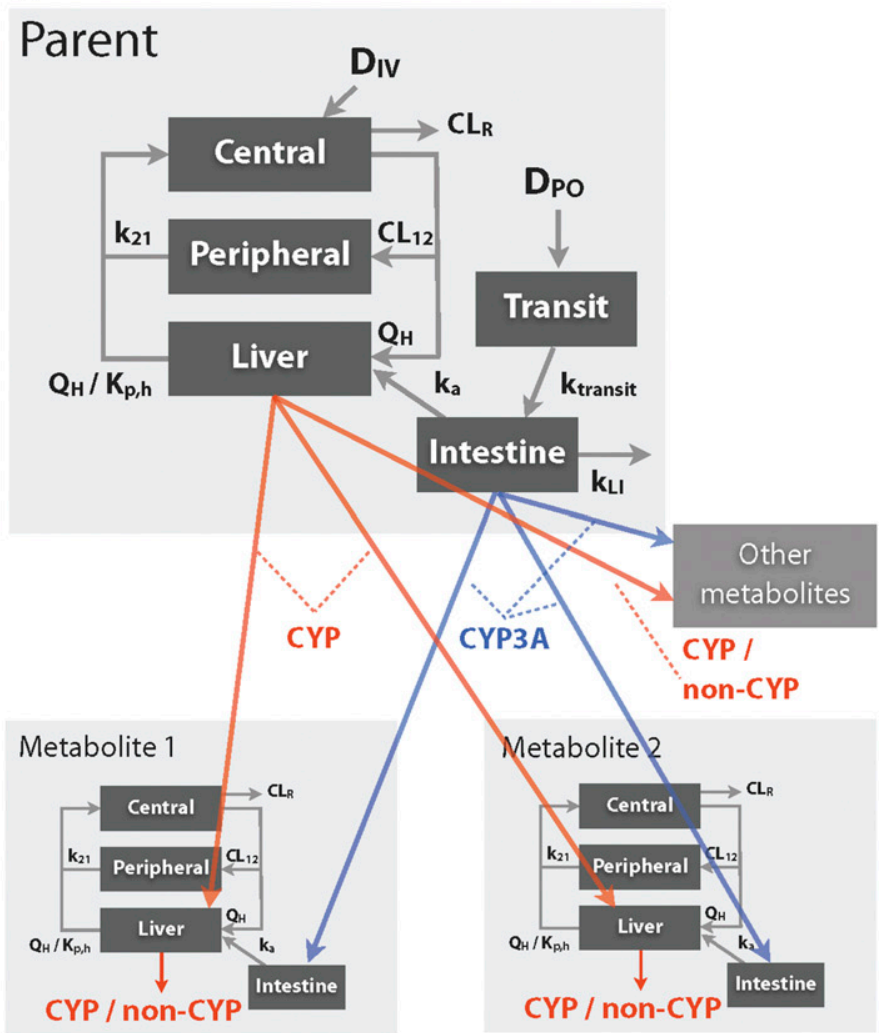

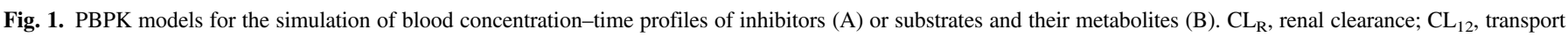

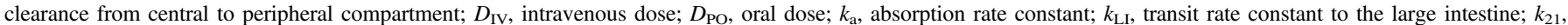
transport rate constant from peripheral to central compartment; $Q_{\mathrm{H}}$, hepatic blood flow rate.

exceptions were desipramine, flurbiprofen, imipramine, and oxycodone, for which higher ranges $(0.3-300)$ were needed to reproduce the clinical observations.

The initial range of $K_{\mathrm{p}, \mathrm{h}}$ was set as $0.03-30$. The initial range of $K_{\mathrm{i} \text {,total }}$ was set as 1000 -fold containing maximum blood concentrations of inhibitors. The initial range of $R_{\mathrm{MBI}}-1$ was set as $1-100$. The initial range of $R_{\text {intes,3A }}-1$ for quinidine or fluconazole was set as $0.03-30$ or $0.1-100$, respectively.

The fixed parameter values and initial parameter ranges are summarized in Table 3 and Supplemental Tables 1-17.

Transformations of Parameters. To apply limitations to the parameter values, the following parameter transformation was performed:

$$
X=\ln \left(x-x_{\text {limits, } \min }\right)
$$

where $x, X$, and $x_{\text {limits,min }}$ denote the original parameters, transformed parameters, and lower limits of the original parameters (different from the minimum values in the parameter ranges), respectively. After parameter optimization using transformed parameters, the original parameter values and standard deviations were calculated using the following equation:

$$
x=\exp X+x_{\text {limits }, \min }
$$

All parameters had $x_{\text {limits,min }}$ of 0 , except for $V_{c}(0.0741 / \mathrm{kg}$; blood volume $)$ (Davies and Morris, 1993).

Parameter Estimations with CNM. CNM, which had been constructed previously (Yoshida et al., 2013; Aoki et al., 2014), was used in the parameter estimations in this study, using the objective values summarized in Tables 1 and 2. Briefly, a group of initial parameter sets (1000 or 2000 virtual parameter sets for the analyses of inhibitor or substrate pharmacokinetics, respectively) was prepared with a random sampling from given parameter ranges. The linear approximations of the projections from one group of parameter sets $\left(X_{\mathrm{b}}\right)$ into the objective values would generate the next group $\left(X_{\mathrm{a}}\right)$. We calculated internally dividing point $X_{\mathrm{i}}$ with the ratio of $\mathrm{dS}:(1-\mathrm{dS})$, and applied the same inverse matrix to obtain the new estimated parameters $X_{\mathrm{a}}{ }^{\prime}$. The value of dS was arbitrary set as 0.5 .

The parameter sets for the next iteration were obtained by randomly selecting $X_{\mathrm{a}}$ or $X_{\mathrm{a}}{ }^{\prime}$ for each virtual sample. Ten or 15 iterations of this process yielded a group of optimized parameter sets in the analyses of inhibitor or substrate pharmacokinetics, respectively. The sum of squares of $\log$ residuals for the objective function $\mathrm{Y}\left(\mathrm{SS}_{\mathrm{log}, \mathrm{Y}}, \mathrm{AUC}\right.$ or $\mathrm{A}_{\mathrm{e}}$, as summarized in Tables 1 and 2 ) were calculated in each iteration to evaluate the goodness of fit with the following equation:

$$
\mathrm{SS}_{\log , \mathrm{Y}}=\sum\left(\ln \frac{Y_{\text {simulated }}}{Y_{\text {observed }}}\right)^{2}
$$

After completing the estimations of parameters, we compared the concentration time-profiles with the observed profiles, using the sum of squares of $\log$ residuals $\left(\mathrm{SS}_{\log , \text { time }}\right)$ :

$$
\mathrm{SS}_{\text {log,time }}=\sum\left(\ln \frac{C_{\text {simulated }}}{C_{\text {observed }}}\right)^{2}
$$

where $C_{\text {simulated }}$ and $C_{\text {observed }}$ represent the simulated or observed blood concentrations at each time point. The reliability of the parameter estimates was assessed by summary statistics of 30 parameter sets reproducing concentrationtime profiles with low $\mathrm{SS}_{\log \text {,time }}$.

Computations. Parameter estimations with CNM, including the use of the ODE15S function to numerically solve ordinary differential equations, were performed under MATLAB software environments using a desktop computer (CPU: Core i7-870 $2.93 \mathrm{GHz} \times 1$, OS: Windows 7 SP1 32 bit, RAM: 4 GB) (MATLAB version 8.0.0; MathWorks, Natick, MA) or a workstation (CPU: XeonE5-1620 3.60 GHz ×1, OS: CentOS 6.464 bit, RAM: 16 GB) (MATLAB version 8.1.0). 
TABLE 3

Summary of calculated pharmacokinetic parameters fixed in PBPK analyses

If not indicated, pharmacokinetic parameters were derived from the University of Washington Metabolism and Transport Drug Interaction Database (DIDB).

\begin{tabular}{|c|c|c|c|c|c|}
\hline Compound & $K_{\mathrm{p}, \mathrm{h}}{ }^{a}$ & $F_{\mathrm{a}} F_{\mathrm{g}}$ & $R_{\mathrm{B}}$ & $f_{\mathrm{B}}$ & References (PubMed ID) \\
\hline \multicolumn{6}{|l|}{ Substrates } \\
\hline Chlorpromazine & $-b$ & 0.685 & 0.78 & & $10534321,^{c}$ \\
\hline Desipramine & $-b$ & $1.03^{d}$ & 0.89 & & 3365915 \\
\hline Fentanyl & $-b$ & & $1^{e}$ & & 6121896 \\
\hline Flurbiprofen & $-b$ & $>1^{d}$ & 0.56 & & $f$ \\
\hline Hydrocodone & $-b$ & $1^{e}$ & $1^{e}$ & & \\
\hline Imipramine & $-b$ & 0.97 & 1.1 & & 6429693,10534321 \\
\hline Lansoprazole & $-b$ & $1.97^{d}$ & 0.56 & & 8803522,20056146 \\
\hline Losartan & $-b$ & 0.896 & $0.6^{g}$ & & 8529329 \\
\hline Omeprazole & $-b$ & $1.83^{d}$ & 0.58 & & 3858978 \\
\hline Oxycodone & $-b$ & $1.05^{d}$ & 1.3 & & 19417618,22798176 \\
\hline Ropivacaine & $-b$ & & 0.69 & & 11322176 \\
\hline \multicolumn{6}{|l|}{ Inhibitors } \\
\hline Fluconazole & 0.647 & $-b$ & 1 & 0.89 & 18483837 \\
\hline Fluoxetine & 13.6 & 0.722 & 0.96 & 0.063 & 18483837 \\
\hline Fluvoxamine & 12.1 & 0.971 & 1 & 0.23 & 18483837 \\
\hline Itraconazole & 6.38 & 0.885 & 0.58 & 0.062 & 18483837,17495874 \\
\hline Quinidine & 11.6 & 0.869 & 0.92 & 0.14 & 18483837 \\
\hline Voriconazole & 0.562 & 1 & $1^{e}$ & 0.42 & \\
\hline
\end{tabular}

$F_{\mathrm{a}} F_{\mathrm{g}}$, intestinal availability; $R_{\mathrm{B}}$, blood-to-plasma concentration ratio.

${ }^{a}$ Predicted with the reported in silico methods (Rodgers et al., 2005; Rodgers and Rowland, 2006).

${ }^{b}$ Estimated in the following PBPK analysis.

${ }^{c}$ Thummel et al. 2010.

${ }^{d} \mathrm{~F}_{\mathrm{a}} \mathrm{F}_{\mathrm{g}}$ calculated to be $>1$ was fixed as 1 for PBPK analysis.

${ }^{e}$ Assumed to be equal to 1 .

${ }^{f}$ Tono et al. 1992.

${ }^{g}$ Assumed to be equal to 0.6

\section{Results}

Collection of Information of DDIs and Metabolic Enzymes that Interact with Substrates or Inhibitors. Twenty-four cases of clinical DDIs from 17 reports with eight inhibitors (Tables 1 and 2) in which pharmacokinetic alterations of the substrate drug metabolites as well as substrate parent drugs were reported were collected from the DIDB (Hachad et al., 2010). AUCR of substrates ranged from 1.11 to 10.6 (mean: 2.49, median: 1.79). Our literature review for in vitro data using the DIDB suggested the formations of substrate metabolites quantified in the DDI reports were mediated by specific CYP enzymes, except for the formations of 7-hydroxy chlorpromazine (CYP1A2 and 2D6), 5-hydroxy lansoprazole (CYP2C19 and 3A), 5-hydroxy omeprazole (CYP2C19 and 3A), and EXP3194 (CYP2C9 and 3A).

Evaluation of the in vitro inhibition potency of the inhibitors by the static model with in vitro inhibition parameters and clinical inhibitor concentration in plasma (see Materials and Methods) suggested that there were 4, 6, 8, and 13 DDI cases involving CYP2C9, CYP2C19, CYP2D6, and CYP3A as putative enzymes (Table 2). It also suggested that the inhibitor affected the activity of only one CYP enzyme in the liver in all the collected DDIs, except for the effect of fluconazole on losartan elimination (CYP2C9 and CYP3A) and fluoxetine on imipramine elimination (CYP2C19, CYP 2D6, and CYP3A). The effects of clarithromycin on CYP3A, fluoxetine on CYP2C19 and CYP3A, and paroxetine on CYP2D6 were reported to involve MBI, whereas the others involved reversible inhibitions.

Analyses of Inhibitor Pharmacokinetic Profiles with PBPK Models. The blood concentration-time profiles of inhibitors in collected DDIs (Table 1) were analyzed using PBPK models (Fig. 1a). We obtained 1000 or 2000 parameter sets reproducing the objective values (minimizing $\mathrm{SS}_{\log , \mathrm{Y}}$ ) with CNM. Among these, we obtained parameter sets that could reproduce the time profiles of inhibitor blood concentrations (minimizing $\mathrm{SS}_{\text {log,time }}$ ) (Supplemental Figs. 1-6; Supplemental Tables 1-6).
The geometric coefficient of variation $(\mathrm{CV})$ of $\mathrm{f}_{\mathrm{B}} \mathrm{CL}_{\mathrm{int}}$ was small (less than $20 \%$ ) for all inhibitors after the parameter estimations using $\mathrm{AUC}_{\mathrm{inf}}$ as an objective function, particularly when the single-dose pharmacokinetics were analyzed. In the case of fluconazole, for which the time profiles after oral and intravenous administration were simultaneously analyzed, the geometric $\mathrm{CV}$ of $F_{a} F_{g}$ was small (2.14\%). The geometric $\mathrm{CV}$ of most of the other parameters was large ( $>100 \%$ in many cases), suggesting that point estimates of these parameters were not possible only from clinical DDI data.

Analyses of the Effects of Inhibitors on Pharmacokinetic Profiles of Substrates with PBPK Models. The effects of inhibitors on blood concentration-time profiles of substrates in collected DDIs (Table 2) were analyzed using PBPK models (Fig. 1B), with or without including substrate metabolite pharmacokinetic profiles in the analyses. The urinary accumulation of substrate metabolites was analyzed when systemic exposure data were not available (hydroxyl metabolites of imipramine and desipramine). We obtained 1000 or 2000 parameter sets reproducing the objective values (minimizing $\mathrm{SS}_{\mathrm{log}, \mathrm{Y}}$ ) with $\mathrm{CNM}$. Among these, we obtained parameter sets that could reproduce time profiles of the blood concentrations of the substrate parent drug and substrate metabolite (minimizing $\mathrm{SS}_{\text {log,time}}$ ) (Fig. 2; Supplemental Figs. 7-17; Supplemental Tables 7-17).

The geometric $\mathrm{CV}$ of the $f_{\mathrm{B}} \mathrm{CL}_{\text {int }}$ values was small for all cases of analysis (mostly around or less than 20\%), regardless of whether the information on the substrate metabolite was included in the analysis. In 17 out of 24 cases, inclusion of the substrate metabolite information improved the parameter estimation for $K_{\mathrm{i}}$ and $f_{\mathrm{m}}$, as suggested by the smaller geometric CV of parameter estimates (Fig. 3). Conversely, inclusion of the substrate metabolite information in the analysis had a smaller effect on the accuracy of the estimated $f_{\mathrm{m}}$ and $K_{\mathrm{i}}$ in DDIs between chlorpromazine and quinidine, lansoprazole and fluvoxamine, losartan and fluconazole, and omeprazole and fluvoxamine. The geometric CV of most of the other parameters was large $(>100 \%$ in many cases), suggesting that point estimates of these parameters were not possible.

Cross-Study Comparison and Comparison with In Vitro Estimates for $f_{\mathbf{m}}$. Among the DDI cases for which inclusion of substrate metabolite information improved reliability of $K_{\mathrm{i}}$ or $f_{\mathrm{m}}$ estimates (Fig. 3A), $f_{\mathrm{m}}$ of substrates and $K_{\mathrm{i}}$ of inhibitors were compared with each other (Supplemental Fig. 18; Tables 4 and 5). The estimated values of $f_{\mathrm{m}}$ under multiple conditions (different inhibitors or doses of inhibitors) were consistent for desipramine, flurbiprofen, imipramine, and oxycodone (Supplemental Fig. 18; Tables 4 and 5).

On the other hand, the $f_{\mathrm{m}}$ values of fentanyl estimated from two different DDI cases were not equivalent. The estimated $f_{\mathrm{m}}$ of one CYP enzyme in the overall eliminations of substrates was also in fair agreement with in vitro estimates, both for enzymes with a large contribution [CYP2C9 for flurbiprofen (Yamazaki et al., 1998), CYP2D6 for desipramine (McGinnity et al., 2008), and CYP3A for oxycodone (Lalovic et al., 2004)] and those with a small-to-moderate contribution [CYP2D6 for hydrocodone (Hutchinson et al., 2004), imipramine (McGinnity et al., 2008), or oxycodone (Lalovic et al., 2004), and CYP3A for fentanyl (Guitton et al., 1997), lansoprazole (Naritomi et al., 2004), or ropivacaine (Ekström and Gunnarsson, 1996)].

Cross-Study Comparison and Comparison with In Vitro or Previous PBPK Estimates for $\boldsymbol{K}_{\mathrm{i}}$. The estimated in vivo $K_{\mathrm{i}}$ in the studies where metabolite information improved the parameter estimates was compared with each other and with in vitro $K_{\mathrm{i}}$. Because $K_{\mathrm{i} \text {,total }}$ in the PBPK model was defined against hepatic total (bound + unbound) inhibitor concentration, in vivo unbound $K_{\mathrm{i}}$ was calculated for comparison as $f_{\mathrm{B}} \times\left(K_{\mathrm{i}, \text { total }} / K_{\mathrm{p}, \mathrm{H}}\right)$, assuming that the unbound inhibitor 


\section{|}

A Parent

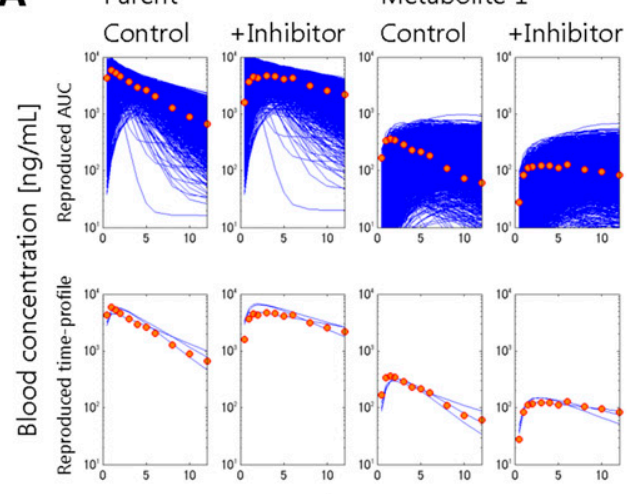

hour

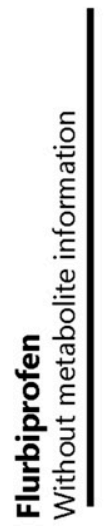

C

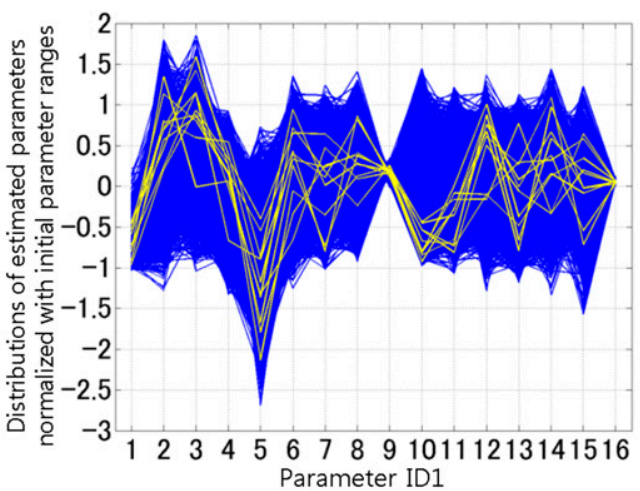

D

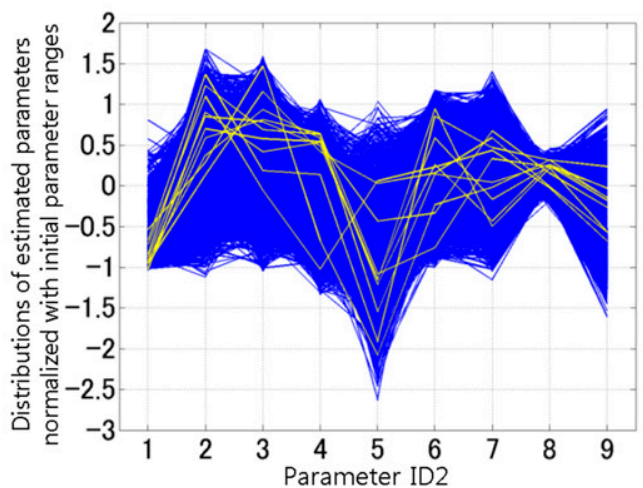

E

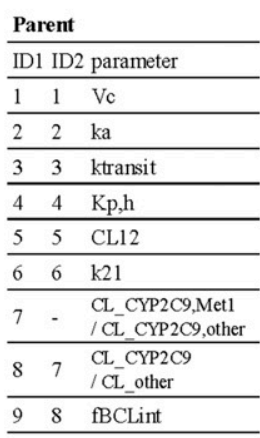

Metabolite 1

\begin{tabular}{ll}
\hline $10-$ & $\mathrm{Vc}$ \\
\hline $11-$ & $\mathrm{Kp}, \mathrm{h}$ \\
\hline $12-$ & $\mathrm{CL} 12$ \\
\hline $13-$ & $\mathrm{k} 21$ \\
\hline $14-$ & $\mathrm{CL}$ R,int,app \\
\hline $15-\mathrm{fBCLint}$ \\
\hline Inhibitor \\
\hline 169 & $\mathrm{Ki}$ CYP2C9 \\
\hline
\end{tabular}

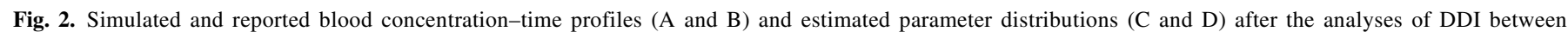

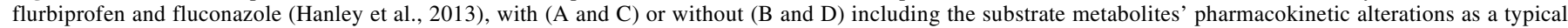

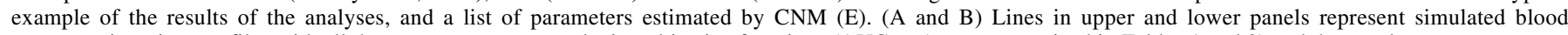

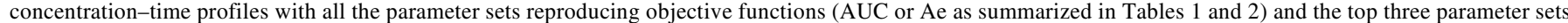

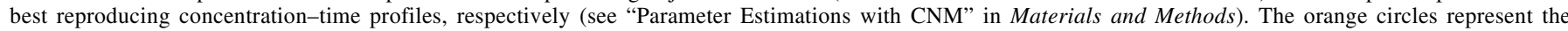

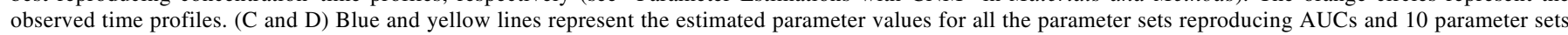

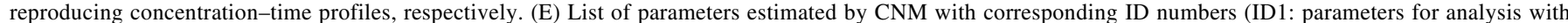

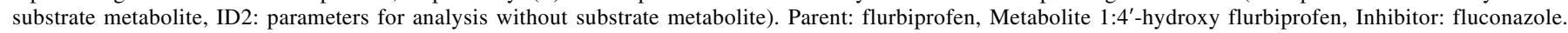

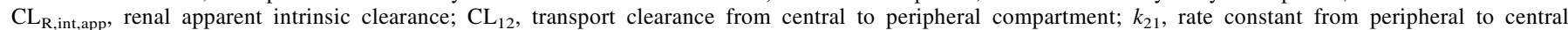
compartment.

concentration in the hepatocyte was the same as the unbound hepatic blood concentration $\left(K_{\mathrm{p}, \mathrm{H}}=f_{\mathrm{B}} / f_{\mathrm{T}}\right)$.

As for the same combinations of inhibitors and CYP enzymes, estimated $K_{\mathrm{i}}$ by the analyses of different DDIs showed similar values among the different reports (Supplemental Fig. 18; Tables 4 and 5). In all cases where comparison was possible, the interstudy variation of the obtained $K_{\mathrm{i}}$ was narrower than the reported ranges obtained from the previous PBPK analyses of clinical DDIs (Kato et al., 2008). The obtained $K_{\mathrm{i}}$ of fluconazole for CYP2C9 or CYP3A and voriconazole for CYP3A was comparable to the median of the collected in vitro $K_{\mathrm{i}}$, whereas the $K_{\mathrm{i}}$ of fluoxetine for CYP2D6, itraconazole on CYP3A, and quinidine for CYP2D6 was 100-1000-fold lower than the in vitro $K_{\mathrm{i}}$.

\section{Discussion}

In this study, we aimed to accurately estimate the two most important parameters, $K_{\mathrm{i}}$ and $f_{\mathrm{m}}$, for determining the degree of pharmacokinetic DDIs (Brown et al., 2005; Obach et al., 2006), based on clinical DDI data where pharmacokinetic alterations of not only substrates but also substrate metabolites has been analyzed. Because some substrate metabolites are produced by a specific enzyme, we hypothesized that use of the substrate metabolites' pharmacokinetic profiles can improve an estimation of the effect of inhibitors on each CYP enzyme in vivo, leading to accurate estimations of the above two parameters.

First, we determined the pharmacokinetic parameters for the inhibitors. Then, using the fixed parameter sets, we performed PBPK analyses of the substrate parent drugs and/or substrate metabolites. As shown in Fig. 2, multiple solutions (i.e., parameter sets) could account for the time profiles of the blood concentration of substrates and their metabolites. Some parameters are convergent across the solutions, whereas additional information or constraint is necessary for the other parameters to be convergent.

We estimated the $f_{\mathrm{B}} \mathrm{CL}_{\mathrm{int}}$ of both substrates and inhibitors with a small geometric $\mathrm{CV}$ among these 30 parameter sets (Supplemental Figs. 1-17). Because we estimated the parameters to reproduce $\mathrm{AUC}_{\mathrm{inf}}$ or AUC with $\mathrm{CNM}$, the small geometric $\mathrm{CV}$ of $f_{\mathrm{B}} \mathrm{CL}_{\text {int }}$ in all the substrates and inhibitors was reasonable. By contrast, the estimated $f_{\mathrm{B}} \mathrm{CL}_{\text {int }}$ of the substrate metabolites showed a large geometric $\mathrm{CV}$ ( $>100 \%$ in most cases). Because exposure of the substrate metabolites is determined not only by their elimination rate but also by the formation rate, multiple solutions are allowed to account for the AUC of the substrate metabolites.

As we hypothesized, the estimated $f_{\mathrm{m}}$ and $K_{\mathrm{i}}$ values showed smaller geometric CVs for many (17 out of 24) studies when the pharmacokinetics 


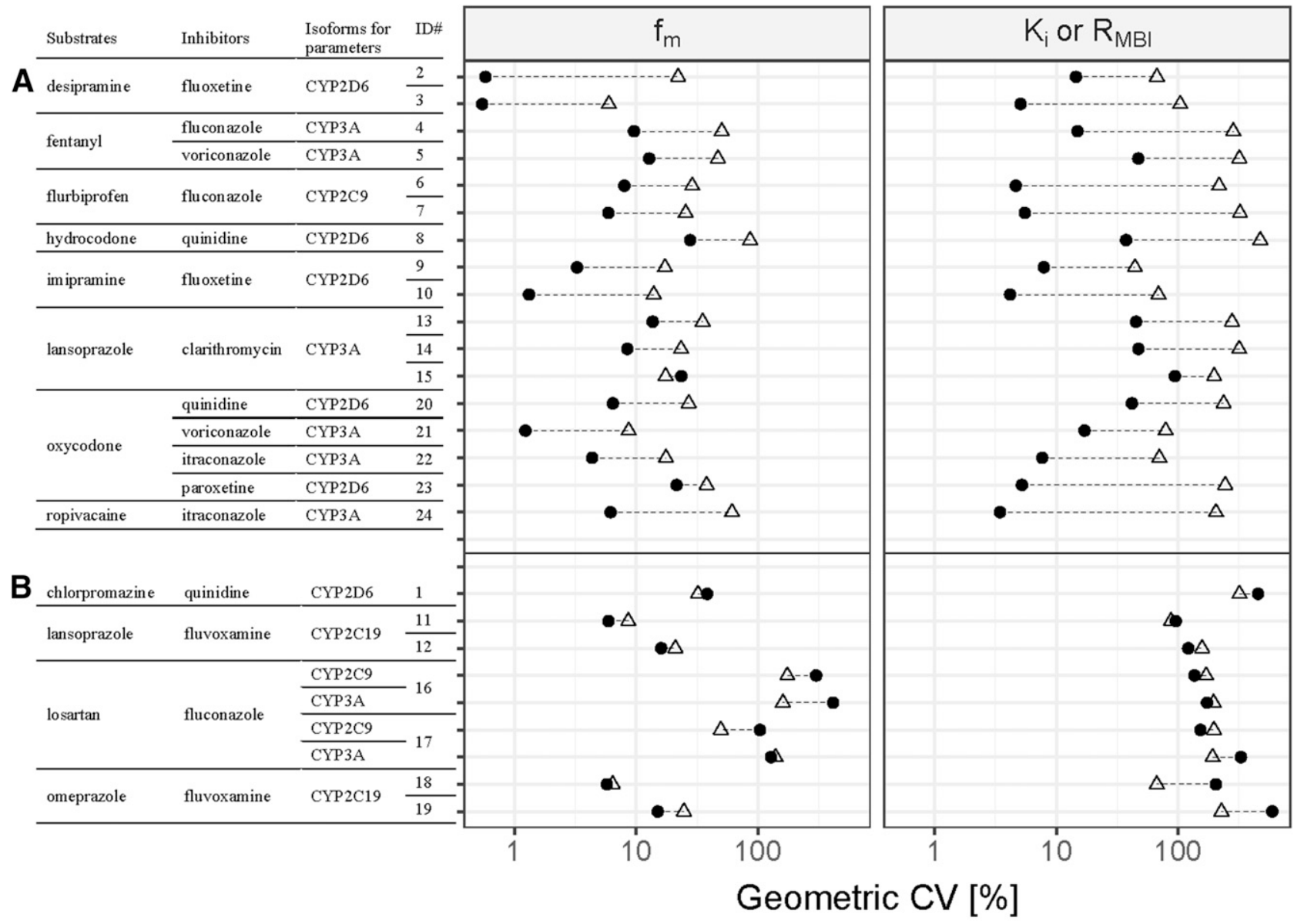

\section{- With metabolite $\Delta$ Without metabolite}

Fig. 3. Comparison of the coefficient of variation for $f_{\mathrm{m}}$ and $K_{\mathrm{i}, t \mathrm{t})} / R_{\mathrm{MBI}}$ estimates, with or without including substrate metabolites' pharmacokinetic profiles in the PBPK analyses. (a) DDI cases for which inclusion of substrate metabolite information reduced the geometric CV of these parameters by at least 2-fold. (b) DDI cases for which inclusion of substrate metabolite information did not reduce the geometric CV. Closed circles and open triangles represent the geometric CV of $f_{\mathrm{m}}$ or $K_{\mathrm{i}, \text { total }} / R_{\mathrm{MBI}}$, estimated with and without including substrate metabolites' pharmacokinetic profiles, respectively. ID of studies analyzed corresponds to those listed in Table 2 . CV, coefficient of variation; $R_{\mathrm{MBI}}$, degree of inhibition with mechanism-based inhibitors.

of both the parent drugs and the metabolites of substrates were analyzed, compared with those estimated when only the pharmacokinetics of the parent substrates were analyzed (Fig. 3). These parameters were reliably estimated even from DDIs in which the parent AUCR $<1.5$ (fentanylfluconazole or voriconazole, hydrocodone-quinidine, oxycodonequinidine or paroxetine, ropivacaine-itraconazole), suggesting that the substrate metabolite can be a novel source of information for DDI analyses.

The $K_{\mathrm{i}}$ obtained from the analyses of multiple clinical DDIs showed small variation across the reports when the same combinations of inhibitors and target CYP enzymes were examined (Fig. 4; Supplemental Fig. 18; Tables 4 and 5). Moreover, similar $K_{\mathrm{i}}$ values of fluoxetine were obtained in the clinical studies where fluoxetine was given in single and multiple doses (Fig. 4). Such small interstudy variations in estimated $f_{\mathrm{m}}$ and $K_{\mathrm{i}}$ suggest the extrapolatability of these parameters to untested scenarios (different substrate/inhibitor/dosing regimen) and may guarantee the reasonable prediction of DDIs in future studies.

On the other hand, this approach has some limitations. For several DDIs, the inclusion of substrate metabolite information in the analyses could not substantially contribute to reducing the geometric $\mathrm{CV}$ in estimated $f_{\mathrm{m}}$ and $K_{\mathrm{i}}$, such as DDIs between chlorpromazine and quinidine, lansoprazole and fluvoxamine, losartan and fluconazole, or omeprazole and fluvoxamine. The common characteristics of these DDIs are that multiple isoforms of CYP enzymes catalyze the formation of the substrate metabolites. Thus, uncertainty in the contribution of enzymes may inhibit convergence of $f_{\mathrm{m}}$ and $K_{\mathrm{i}}$ and additional information is needed, such as the contribution of each CYP isoform to substrate metabolite formation.

The estimated $K_{\mathrm{i}}$ values were compared with those reported by Kato et al. (2008) and those determined in vitro (Fig. 4). Interstudy variabilities in the estimated $K_{\mathrm{i}}$ were narrower than those obtained by conventional PBPK analyses. When compared with in vitro $K_{\mathrm{i}}$, the estimated values for two inhibitors (fluconazole and voriconazole) were comparable to the median of collected in vitro $K_{\mathrm{i}}$ (Fig. 4). For fluoxetine, itraconazole, and quinidine, the estimated $K_{\mathrm{i}}$ was much lower than the in vitro $K_{\mathrm{i}}$ (Fig. 4). For these inhibitors, predictions of DDIs using in vitro $K_{\mathrm{i}}$ would result in underestimations of the degree of DDIs, as pointed out previously elsewhere (Isoherranen et al., 2004; Lutz and Isoherranen, 2012).

Kato et al. (2008) previously suggested that in vivo $K_{\mathrm{i}}$ was generally smaller than in vitro experimental $K_{\mathrm{i}}$, whose discrepancies apparently depend on the lipophilicity of substrates. In our analyses, especially for highly lipophilic itraconazole, our obtained $K_{\mathrm{i}}$ was closer to the in vivo $K_{\mathrm{i}}$ reported by Kato et al. (2008) rather than 
TABLE 4

Estimated parameter values for $f_{\mathrm{m}}$ for DDI cases

The table only includes DDI cases for which the inclusion of substrate metabolite information improved the geometric CV (Fig 3A). Parameter estimates represent summary statistics of 30 parameter sets reproducing concentration-time profiles (low $\mathrm{SS}_{\text {log,time}}$ ). Refer to Table 2 for details of DDI information with corresponding ID number.

\begin{tabular}{|c|c|c|c|c|c|}
\hline Substrates & Inhibitors & Isoforms for Parameters & ID Number & Geometric Mean & $\begin{array}{c}\text { Geometric CV } \\
(\%)\end{array}$ \\
\hline \multirow[t]{2}{*}{ Desipramine } & Fluoxetine & CYP2D6 & $2^{a}$ & 0.995 & 0.578 \\
\hline & & & $3^{b}$ & 0.959 & 0.543 \\
\hline \multirow[t]{2}{*}{ Fentanyl } & Fluconazole & CYP3A & 4 & 0.472 & 9.59 \\
\hline & Voriconazole & CYP3A & 5 & 0.732 & 12.8 \\
\hline \multirow{2}{*}{ Flurbiprofen } & Fluconazole & CYP2C9 & 6 & 0.945 & 7.99 \\
\hline & & & 7 & 0.964 & 5.91 \\
\hline Hydrocodone & Quinidine & CYP2D6 & 8 & 0.512 & 27.7 \\
\hline \multirow{2}{*}{ Imipramine } & Fluoxetine & CYP2D6 & $9^{a}$ & 0.697 & 3.26 \\
\hline & & & $10^{b}$ & 0.752 & 1.32 \\
\hline \multirow[t]{3}{*}{ Lansoprazole } & Clarithromycin & CYP3A & $13^{c}$ & 0.318 & 13.6 \\
\hline & & & $14^{d}$ & 0.483 & 8.46 \\
\hline & & & $15^{e}$ & 0.662 & 23.4 \\
\hline \multirow[t]{4}{*}{ Oxycodone } & Quinidine & CYP2D6 & 20 & 0.253 & 6.44 \\
\hline & Voriconazole & CYP3A & 21 & 0.826 & 1.23 \\
\hline & Itraconazole & CYP3A & 22 & 0.845 & 4.35 \\
\hline & Paroxetine & CYP2D6 & 23 & 0.184 & 21.5 \\
\hline Ropivacaine & Itraconazole & CYP3A & 24 & 0.338 & 6.16 \\
\hline
\end{tabular}

$\mathrm{CV}$, coefficient of variation

${ }^{a}$ Fluoxetine single dose.

${ }^{b}$ Fluoxetine multiple dose.

${ }^{c}$ CYP2C19 extensive metabolizer (EM).

${ }^{d} \mathrm{CYP} 2 \mathrm{C} 19$ intermediate metabolizer (IM)

${ }^{e} \mathrm{CYP} 2 \mathrm{C} 19$ poor metabolizer (PM).

in vitro $K_{\mathrm{i}}$. The inconsistency of the in vitro and in vivo $K_{\mathrm{i}}$ values may be attributable to the following mechanisms: the additional contribution of P-glycoprotein inhibition (Benet et al., 2004), inaccurate estimations of blood unbound fractions of inhibitors, or incubation buffer for in vitro experiments (Thompson et al., 1988; Arredondo et al., 1999; Templeton et al., 2008), extensive accumulation of inhibitors into hepatocytes as seen in itraconazole (Yamano et al., 1999), or additional inhibition by inhibitor metabolites (Otton et al., 1993; Ching et al., 1995; Isoherranen et al., 2004; Templeton et al., 2008; Isoherranen et al., 2009; Lutz and Isoherranen, 2012).

In the reports cited in this study, plasma concentrations of inhibitor metabolites were not measured, and the contribution of inhibitor metabolites was not taken into account in the PBPK analysis. Including such information may partly address the observed inconsistencies. Furthermore, due to the limited available data for each inhibitor with different experimental conditions, we did not exclude the in vitro studies that did not measure the unbound fraction of inhibitors in an incubation buffer, which could partly explain the interstudy variation of in vitro $K_{\mathrm{i}}$ values (Fig. 4). Interestingly, the lowest in vitro $K_{\mathrm{i}}$ of itraconazole $(1 \mathrm{nM})$ was obtained in an experiment with a low microsome concentration in the incubation buffer $(0.025 \mathrm{mg} / \mathrm{ml})$ after correction with the unbound fraction (Isoherranen et al., 2004). This result appears to support the importance of accurately estimating the effective inhibitor concentration in the incubation buffer. For CYP3A, it is also possible that $K_{\mathrm{i}}$ of inhibitors sometimes depend on the substrates tested (Fowler and Zhang, 2008). We will be able to partly bridge the gap between

TABLE 5

Estimated parameter values for $K_{\mathrm{i}}$ for DDI cases

The table only includes DDI cases for which the inclusion of substrate metabolite information improved the geometric CV (Fig 3A). Parameter estimates represent summary statistics of 30 parameter sets reproducing concentration-time profiles (low $\mathrm{SS}_{\text {log,time) }}$. Refer to Table 2 for details of DDI information with corresponding ID number.

\begin{tabular}{llcccc}
\hline \multirow{2}{*}{ Inhibitors } & Substrates & Isoforms for Parameters & ID Number & $\begin{array}{c}\text { Geometric Mean } \\
(\mu \mathrm{M})\end{array}$ & $\begin{array}{c}\text { Geometric CV } \\
(\%)\end{array}$ \\
\hline \multirow{2}{*}{ Fluconazole } & Fentanyl & CYP3A & 4 & 7.73 & 14.9 \\
& Flurbiprofen & CYP2C9 & 6 & 17 & 4.64 \\
& & & 7 & 19.9 & 5.51 \\
Fluoxetine & Desipramine & CYP2D6 & $2^{a}$ & 0.000195 & 14.5 \\
& & & $3^{b}$ & 0.000127 & 5.09 \\
& Imipramine & & $9^{a}$ & 0.000177 & 7.9 \\
Itraconazole & Oxycodone & CYP3A & $10^{b}$ & 0.000149 & 4.17 \\
Quinidine & Ropivacaine & & 22 & 0.000115 & 7.67 \\
& Hydrocodone & CYP2D6 & 24 & 0.000103 & 3.45 \\
Voriconazole & Oxycodone & & 8 & 0.0000977 & 37.4 \\
& Oxycodone & CYP3A & 20 & 0.000552 & 41.8 \\
& & & 5 & 1.71 & 47.1 \\
\hline
\end{tabular}

$\mathrm{CV}$, coefficient of variation

${ }^{a}$ Fluoxetine single dose.

${ }^{b}$ Fluoxetine multiple dose. 


\section{A fluconazole CYP2C9}
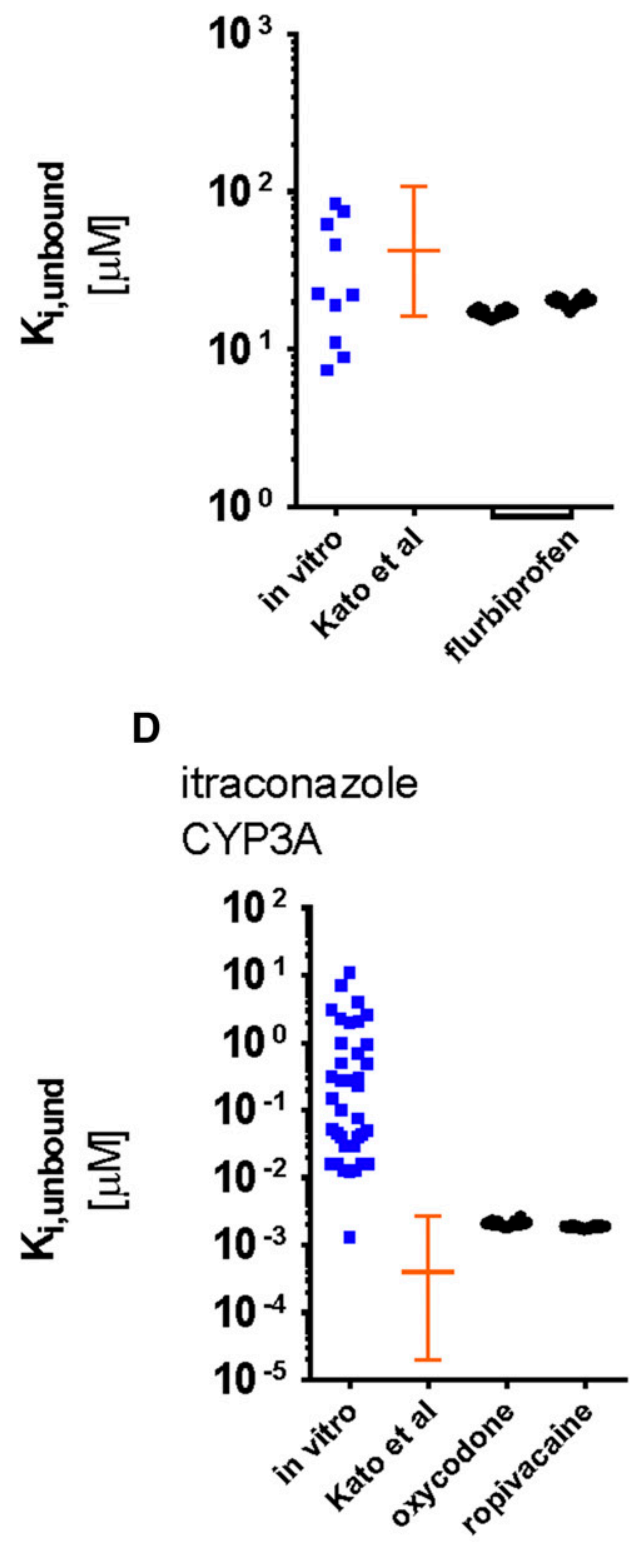

B
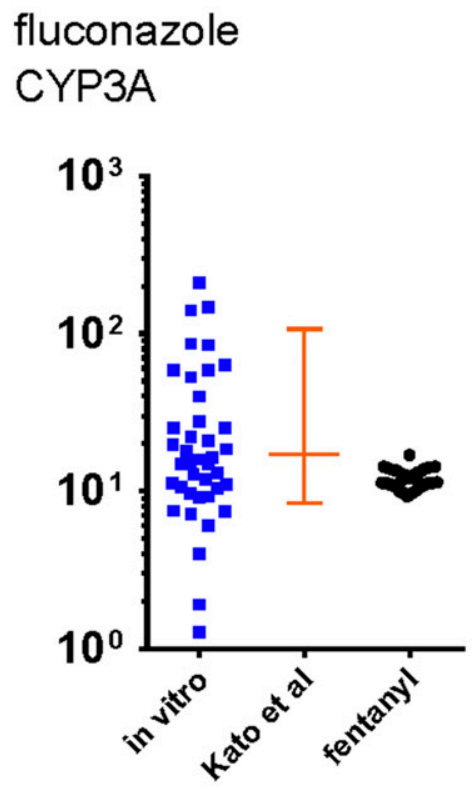

E

quinidine
CYP2D6

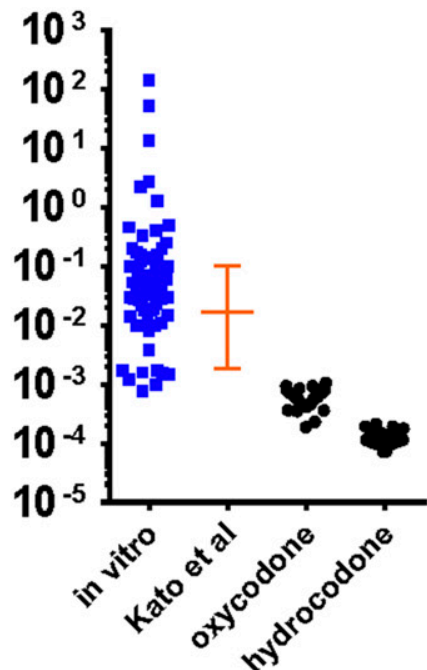

C fluoxetine CYP2D6

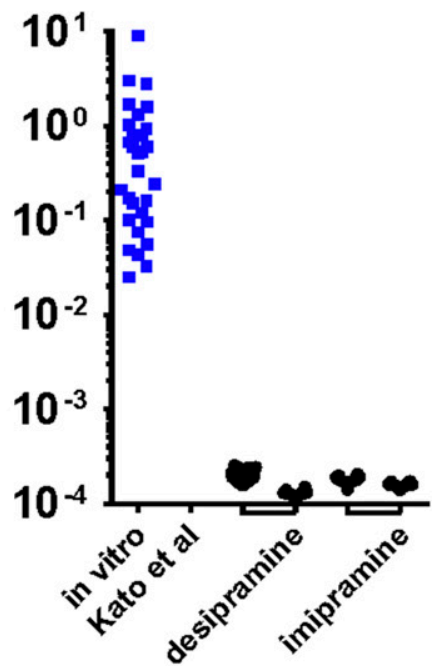

F

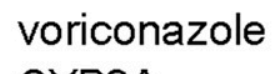

CYP3A

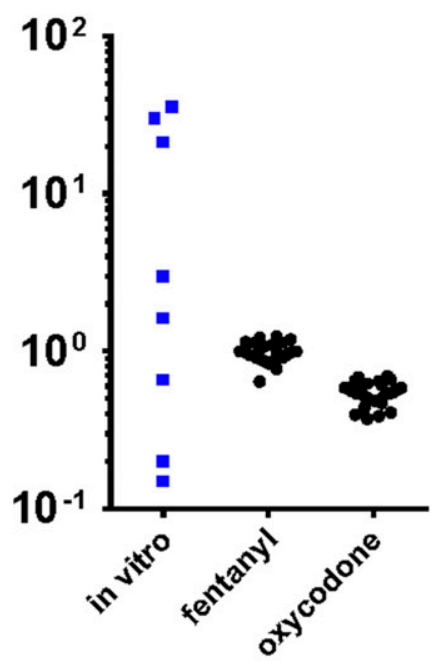

Fig. 4. Comparison of the estimated $\mathrm{K}_{\mathrm{i} \text {,unbound }}$ with reported values obtained with in vitro experiments or with conventional PBPK analyses of drug-drug interactions caused by the inhibition of CYP2C9 by fluconazole (A), CYP3A by fluconazole (B), CYP2D6 by fluoxetine (C), CYP3A by itraconazole (D), CYP2D6 by quinidine (E), and CYP3A by voriconazole (F) without substrate metabolites' pharmacokinetic information. Circles represent $K_{\mathrm{i}, \text { unbound }}$ for the estimated parameter sets with 30 lowest $\mathrm{SS}_{\text {log time }}$ values with PBPK models including substrate metabolites' pharmacokinetic profiles. Each square represents the reported in vitro $K_{\mathrm{i} \text {,unbound }}$ in a report collected from the University of Washington Metabolism and Transport Drug Interaction Database (DIDB). Bars represent the maximum, geometric mean, and minimum values of estimated $K_{\mathrm{i} \text {,unbound }}$ by analyzing drug-drug interactions with PBPK models in the previous report by Kato et al. (2008). $K_{\mathrm{i} \text {,unbound }}$, inhibition constant with regard to unbound inhibitor concentration.

in vitro and in vivo $K_{\mathrm{i}}$ for more accurate predictions of clinical DDIs by carefully optimizing our in vitro experimental approaches.

To predict the impact of DDIs on the pharmacokinetics of new investigational drugs, the contribution of enzymes and transporters must be evaluated accurately. Our results indicated that the $f_{\mathrm{m}}$ values determined by our approach under multiple conditions were estimated to be consistent in most cases (four out of five compounds with multiple DDI studies available for comparison; Supplemental Fig. 18 and Tables 4 and 5), supporting the reliability of the in vivo $f_{\mathrm{m}}$ values of substrates we obtained. As for fentanyl, whose estimated $f_{\mathrm{m}}$ values depended on the reported DDI cases, the original DDI study reported a similar magnitude of change in the parent and metabolite AUC between the voriconazole and fluconazole, while the concentrationtime profiles of norfentanyl appeared to be different (Saari et al., 2008). This inconsistency might have led to different estimates of $f_{\mathrm{m}}$ in two DDI cases.

We must be careful about quantitatively extrapolating in vitro observations into in vivo parameters for new investigational drugs. 
There are two major difficulties in such extrapolations. The first is that in most of these studies the contribution of each CYP enzyme in vitro was estimated by investigating the formation of one or a few metabolite(s) but not the disappearance of substrates. Theoretically, to accurately estimate the overall $f_{\mathrm{m}}$ from metabolite formation data, one must measure the formation of all the metabolites. In particular, when using liver microsomes the contribution of enzymes located in cytosolic fraction or those whose enzymatic reaction requires certain cofactor(s) (e.g., phase II enzymes) cannot be considered, causing overestimation of the contribution of CYP enzymes. Another difficulty is that the activity of each CYP enzyme can be highly dependent on the study design, such as the selection of microsomes (pooled batch, individual batch) and the selection of the medium, including phosphate concentration (Crespi, 1998).

These aspects reinforce the importance of reliably establishing in vivo $f_{\mathrm{m}}$ for developing optimal in vitro experimental conditions. In an ideal scenario of drug development, it is also important to consider the outcomes of mass-balance studies for realizing definitive in vivo $f_{\mathrm{m}}$ estimates, but few data are publicly available at this time.

Our findings suggest an additional factor to consider when selecting probe substrates for clinical DDI studies to improve PBPK model-based parameter estimation. We showed that the specificity of enzymes involved in the formation of the metabolites was important in improving the reliability of $f_{\mathrm{m}}$ and $K_{\mathrm{i}}$ estimates. Current regulatory guidance/guidelines on pharmacokinetic drug interaction recommend conducting clinical DDI studies with in vivo probe substrates, with the predominant contribution of a single enzyme to their overall elimination (http://www.ema.europa.eu/docs/en_GB/document_ library/Scientific_guideline/2012/07/WC500129606.pdf; http://www.fda. gov/downloads/Drugs/GuidanceComplianceRegulatoryInformation/ Guidances/UCM292362.pdf; https://www.pmda.go.jp/files/000225191.pdf). To accurately determine the interaction potential of a new investigational drug as an inhibitor, the selection of substrates with metabolites formed by the specific enzyme of interest (e.g., substrates listed in Fig. $3 \mathrm{~A})$ can be important, in addition to other considerations such as likelihood of comedication.

In conclusion, this study demonstrated the importance of considering pharmacokinetic alterations of substrate metabolites as well as substrate parent drugs in the accurate determination of in vivo $K_{\mathrm{i}}$ and $f_{\mathrm{m}}$ using PBPK modeling. The obtained $K_{\mathrm{i}}$ values should increase the accuracy of the predicted degree of DDIs for untested combinations of substrates and inhibitors.

\section{Authorship Contributions}

Participated in research design: Yoshida, Maeda.

Conducted experiments: Yoshida, Maeda.

Contributed new reagents or analytic tools: Konagaya.

Performed data analysis: Yoshida, Maeda, Kusuhara.

Wrote or contributed to the writing of the manuscript: Yoshida, Maeda, Kusuhara.

\section{References}

Aoki Y, Hayami K, Sterck HD, and Konagaya A (2014) Cluster Newton method for sampling multiple solutions of underdetermined inverse problems: application to a parameter identification problem in pharmacokinetics. SIAM J Sci Comput 36:B14-B44.

Arredondo G, Suárez E, Calvo R, Vazquez JA, García-Sanchez J, and Martinez-Jordá R (1999) Serum protein binding of itraconazole and fluconazole in patients with diabetes mellitus. $J$ Antimicrob Chemother 43:305-307.

Benet LZ, Cummins CL, and Wu CY (2004) Unmasking the dynamic interplay between efflux transporters and metabolic enzymes. Int J Pharm 277:3-9.

Brown HS, Ito K, Galetin A, and Houston JB (2005) Prediction of in vivo drug-drug interactions from in vitro data: impact of incorporating parallel pathways of drug elimination and inhibitor absorption rate constant. Br J Clin Pharmacol 60:508-518.

Ching MS, Blake CL, Ghabrial H, Ellis SW, Lennard MS, Tucker GT, and Smallwood RA (1995) Potent inhibition of yeast-expressed CYP2D6 by dihydroquinidine, quinidine, and its metabolites. Biochem Pharmacol 50:833-837.
Crespi CL (1998) Effect of salt concentration on the activity of liver microsomal and cDNAexpressed human cytochromes P450, in International Symposium on Microsomes \& Drug Oxidations; Montpellier, France. pp 95.

Davies B and Morris T (1993) Physiological parameters in laboratory animals and humans. Pharm Res 10:1093-1095.

Ekström G and Gunnarsson UB (1996) Ropivacaine, a new amide-type local anesthetic agent, is metabolized by cytochromes P450 1A and 3A in human liver microsomes. Drug Metab Dispos 24:955-961

Fowler S and Zhang H (2008) In vitro evaluation of reversible and irreversible cytochrome P450 inhibition: current status on methodologies and their utility for predicting drug-drug interactions. AAPS J 10:410-424.

Guitton J, Buronfosse T, Désage M, Lepape A, Brazier JL, and Beaune P (1997) Possible involvement of multiple cytochrome P450S in fentanyl and sufentanil metabolism as opposed to alfentanil. Biochem Pharmacol 53:1613-1619.

Hachad H, Ragueneau-Majlessi I, and Levy RH (2010) A useful tool for drug interaction evaluation: the University of Washington Metabolism and Transport Drug Interaction Database. Hum Genomics 5:61-72.

Hanley MJ, Masse G, Harmatz JS, Cancalon PF, Dolnikowski GG, Court MH, and Greenblatt DJ (2013) Effect of blueberry juice on clearance of buspirone and flurbiprofen in human volunteers. Br J Clin Pharmacol 75:1041-1052.

Hisaka A, Ohno Y, Yamamoto T, and Suzuki H (2010) Prediction of pharmacokinetic drug-drug interaction caused by changes in cytochrome $\mathrm{P} 450$ activity using in vivo information. Pharmacol Ther 125:230-248.

Houston JB and Galetin A (2008) Methods for predicting in vivo pharmacokinetics using data from in vitro assays. Curr Drug Metab 9:940-951.

Huang SM, Strong JM, Zhang L, Reynolds KS, Nallani S, Temple R, Abraham S, Habet SA Baweja RK, Burckart GJ, et al. (2008) New era in drug interaction evaluation: US Food and Drug Administration update on CYP enzymes, transporters, and the guidance process. $J$ Clin Pharmacol 48:662-670.

Hutchinson MR, Menelaou A, Foster DJ, Coller JK, and Somogyi AA (2004) CYP2D6 and CYP3A4 involvement in the primary oxidative metabolism of hydrocodone by human liver microsomes. Br J Clin Pharmacol 57:287-297.

Isoherranen N, Hachad H, Yeung CK, and Levy RH (2009) Qualitative analysis of the role of metabolites in inhibitory drug-drug interactions: literature evaluation based on the metabolism and transport drug interaction database. Chem Res Toxicol 22:294-298.

Isoherranen N, Kunze KL, Allen KE, Nelson WL, and Thummel KE (2004) Role of itraconazole metabolites in CYP3A4 inhibition. Drug Metab Dispos 32:1121-1131.

Ito K, Iwatsubo T, Kanamitsu S, Ueda K, Suzuki H, and Sugiyama Y (1998) Prediction of pharmacokinetic alterations caused by drug-drug interactions: metabolic interaction in the liver. Pharmacol Rev 50:387-412.

Jones HM, Chen Y, Gibson C, Heimbach T, Parrott N, Peters SA, Snoeys J, Upreti VV, Zheng M, and Hall SD (2015) Physiologically based pharmacokinetic modeling in drug discovery and development: a pharmaceutical industry perspective. Clin Pharmacol Ther 97:247-262.

Kato M, Shitara Y, Sato H, Yoshisue K, Hirano M, Ikeda T, and Sugiyama Y (2008) The quantitative prediction of CYP-mediated drug interaction by physiologically based pharmacokinetic modeling. Pharm Res 25:1891-1901.

Khojasteh SC, Wong H, and Hop CE (2011) Metabolism-based drug interactions, in Drug Metabolism and Pharmacokinetics Quick Guide, pp 73-95, Springer, New York.

Lalovic B, Phillips B, Risler LL, Howald W, and Shen DD (2004) Quantitative contribution of CYP2D6 and CYP3A to oxycodone metabolism in human liver and intestinal microsomes. Drug Metab Dispos 32:447-454.

Lutz JD and Isoherranen N (2012) In vitro-to-in vivo predictions of drug-drug interactions involving multiple reversible inhibitors. Expert Opin Drug Metab Toxicol 8:449-466.

Luzon E, Blake K, Cole S, Nordmark A, Versantvoort C, and Berglund EG (2017) Physiologically based pharmacokinetic modeling in regulatory decision-making at the European Medicines Agency. Clin Pharmacol Ther 102:98-105.

McGinnity DF, Waters NJ, Tucker J, and Riley RJ (2008) Integrated in vitro analysis for the in vivo prediction of cytochrome P450-mediated drug-drug interactions. Drug Metab Dispos 36: $1126-1134$.

Naritomi Y, Terashita S, and Kagayama A (2004) Identification and relative contributions of human cytochrome P450 isoforms involved in the metabolism of glibenclamide and lansoprazole: evaluation of an approach based on the in vitro substrate disappearance rate. Xenobiotica 34:415-427.

Obach RS, Walsky RL, Venkatakrishnan K, Gaman EA, Houston JB, and Tremaine LM (2006) The utility of in vitro cytochrome $\mathrm{P} 450$ inhibition data in the prediction of drug-drug interactions. I Pharmacol Exp Ther 316:336-348.

Otton SV, Wu D, Joffe RT, Cheung SW, and Sellers EM (1993) Inhibition by fluoxetine of cytochrome P450 2D6 activity. Clin Pharmacol Ther 53:401-409.

Rodgers T, Leahy D, and Rowland M (2005) Physiologically based pharmacokinetic modeling 1: predicting the tissue distribution of moderate-to-strong bases. J Pharm Sci 94:1259-1276.

Rodgers T and Rowland M (2006) Physiologically based pharmacokinetic modelling 2: predicting the tissue distribution of acids, very weak bases, neutrals and zwitterions. J Pharm Sci 95: $1238-1257$.

Rowland M, Peck C, and Tucker G (2011) Physiologically-based pharmacokinetics in drug development and regulatory science. Annu Rev Pharmacol Toxicol 51:45-73.

Saari TI, Laine K, Neuvonen M, Neuvonen PJ, and Olkkola KT (2008) Effect of voriconazole and fluconazole on the pharmacokinetics of intravenous fentanyl. Eur J Clin Pharmacol 64:25-30. Templeton IE, Thummel KE, Kharasch ED, Kunze KL, Hoffer C, Nelson WL, and Isoherranen N (2008) Contribution of itraconazole metabolites to inhibition of CYP3A4 in vivo. Clin Pharmacol Ther 83:77-85.

Thompson KA, Murray JJ, Blair IA, Woosley RL, and Roden DM (1988) Plasma concentrations of quinidine, its major metabolites, and dihydroquinidine in patients with torsades de pointes. Clin Pharmacol Ther 43:636-642.

Thummel KE, Shen DD, and Isoherranen N. (2010) Design and optimization of dosage regimens: pharmacokinetic data, in Goodman \& Gilman's The Pharmacological Basis of Therapeutics, 12th ed (Brunton LL, Chabner BA, and Knollmann BC eds), appendix II, McGraw-Hill, New York.

Tono M, Konishi Y, Kojima H, Kawahara K, and Horiba M. (1992) Pharmacokinetics and metabolic studies of LFP83 in man after the single and repeated intravenous administration [in Japanese]. Kiso to Rinsho 26:3907-3921. 
Wagner C, Zhao P, Pan Y, Hsu V, Grillo J, Huang SM, and Sinha V (2015) Application of physiologically based pharmacokinetic (PBPK) modeling to support dose selection: report of an FDA public workshop on PBPK. CPT Pharmacometrics Syst Pharmacol 4: 226-230.

Yamano K, Yamamoto K, Kotaki H, Sawada Y, and Iga T (1999) Quantitative prediction of metabolic inhibition of midazolam by itraconazole and ketoconazole in rats: implication of concentrative uptake of inhibitors into liver. Drug Metab Dispos 27:395-402.

Yamazaki H, Inoue K, Chiba K, Ozawa N, Kawai T, Suzuki Y, Goldstein JA, Guengerich FP, and Shimada T (1998) Comparative studies on the catalytic roles of cytochrome P450 2C9 and its Cys- and Leu-variants in the oxidation of warfarin, flurbiprofen, and diclofenac by human liver microsomes. Biochem Pharmacol 56:243-251.
Yoshida K, Maeda K, Kusuhara H, and Konagaya A (2013) Estimation of feasible solution space using Cluster Newton Method: application to pharmacokinetic analysis of irinotecan with physiologically-based pharmacokinetic models. BMC Syst Biol 7 (Suppl 3):S3.

Address correspondence to: Dr. Hiroyuki Kusuhara, Laboratory of Molecular Pharmacokinetics, Graduate School of Pharmaceutical Sciences, University of Tokyo, 7-3-1 Hongo, Bunkyo-ku, Tokyo 113-0033, Japan. E-mail: kusuhara@mol.f. u-tokyo.ac.jp 